\title{
Effect of grain-scale pressure variations on garnet growth: $A$ numerical approach
}

\section{Journal Article}

Author(s):

Zhong, Xin; Vrijmoed, Johannes C.; Tajčmanová, Lucie

Publication date:

2017-01

Permanent link:

https://doi.org/10.3929/ethz-a-010744283

Rights / license:

In Copyright - Non-Commercial Use Permitted

Originally published in:

Journal of Metamorphic Geology 35(1), https://doi.org/10.1111/jmg.12213

Funding acknowledgement:

335577 - Interplay between metamorphism and deformation in the Earth's lithosphere (EC) 
1 Effect of grain-scale pressure variations on garnet growth: A numerical approach.

3

4 ZHONG X., VRIJMOED J.C. AND TAJČMANOVÁ L. 


\section{ABSTRACT}

Grain-scale pressure variations have recently been investigated due to its significant effect on the observed microstructures and chemical redistribution in metamorphic rocks. In this study, we investigate the impact of grain-scale pressure variation on a growing grain, specifically on garnet. We model prograde garnet growth at fluid saturated conditions and sufficiently low temperature $\left(<650^{\circ} \mathrm{C}\right)$ to avoid modification of the inner part of the grain by diffusion. The method uses the Perple_X computer program package combined with Matlab ${ }^{\circledR}$ scripts allowing for a heterogeneous fluid pressure distribution around the growing grain. It is shown that the pressure variation around the grain may result in an asymmetric chemical zonation. Motivated by the result, we apply the model to selected published prograde paths to evaluate the magnitude of the pressure variation that is necessary for the development of the asymmetric zoning preserved in the samples. The magnitude of such a pressure gradient in the selected samples corresponds up to 1 kbar. Finally, it is demonstrated that the modelling of asymmetric chemical zoning in garnet under a pressure gradient may improve the precision of thermobarometric constraints. The numerical model evaluates the effect of the pressure gradient on a growing grain and thus can serve as a benchmark tool in future development of fully coupled models involving rock deformation and mineral reactions.

Keywords: Asymmetric chemical zoning, garnet, pressure variation, prograde metamorphism, equilibrium thermodynamics. 


\section{INTRODUCTION}

The concept of equilibrium under a pressure gradient has been gradually adopted and emphasized due to its significance on the preserved microstructure and compositional variations in rocks (Tajčmanová et al., 2014; 2015). Pressure variation has been directly measured (e.g. Nasdala et al., 2005; Chen et al., 2015), numerically modeled at different scales (Mancktelow, 1993; Petrini \& Podladchikov, 2000; Moulas et al., 2014; Dabrowski et al., 2015) and systematically investigated on its significance for the preserved chemical zonation (Tajčmanová et al., 2014, 2015; Moulas et al., 2015; Zhong et al., 2015). One of the main causes of grain-scale pressure variation is deformation due to heterogeneous viscosity distribution (Schmid \& Podladchikov 2003; Moulas et al., 2014; Tajčmanová et al., 2015). Another typical example is a radial pressure variation caused by the expansion of a stressed inclusion surrounded by a relaxed host matrix (Zhang, 1998; Tajčmanová et al., 2014; Dabrowski et al., 2015; Angel et al., 2015). Dabrowski et al. (2015) provided an analytical solution to estimate the time scale of viscous pressure relaxation in an inclusion-host system and concluded that it may last up to a million year. Moreover, Tajčmanová et al. (2014) documented the effect of grain scale pressure variation on the preserved chemical zonation in plagioclase at high temperature where diffusion is expected to be significant.

Based on theoretical and experimental studies, fluid pressure has been confirmed to exert the first order control on common metamorphic reactions and mineral growth (Gibbs, 1876; Dahlen, 1992; Llana-Funez et al., 2012, Hobbs \& Ord, 2015). Understanding the development of prograde chemical zoning of a perfectly fractionating grain in the presence of pressure gradients in fluid saturated systems is an important step for further quantitative models of dynamic fluid pressure evolution and mineral reactions during prograde metamorphism. The results of such an idealized fractionating approach could then be used as a benchmark in the development of predictive dynamic models. Therefore, the aim here is to investigate the growth of a mineral along a fluid saturated prograde $P-T$ path under a grain-scale 
fluid pressure gradient.

In the lower crust, the fluid pressure $\left(P_{f}\right)$ is conventionally considered to be equal to the lithostatic pressure $\left(P_{l}\right)$ because fluid is sealed in low porosity and permeability metamorphic rocks (Spear, 1993; Winter, 2010). However, during devolatilization reactions the fluid pressure can deviate from lithostatic at the reaction front (Connolly, 2010; Connolly \& Podladchikov, 2012). In Fig. 1a (modified after Connolly, 2010), such a fluid pressure behavior is depicted. In the area above and below the reaction region, rocks are considered to be compact and the fluid pressure equals to the lithostatic pressure. Within the reaction region, the porosity and permeability are elevated which allows the fluid pressure to follow the hydrostatic gradient (the blue line in Fig. 1a). The hydrostatic gradient is generally lower than the lithostatic pressure gradient because fluids are less dense than rocks (Connolly, 2010). The inequality between the macroscopic fluid pressure and the lithostatic pressure for a continuum in the reaction region illustrated in Fig. 1a has consequences for the microscopic pressure variation at the grain-scale. In Fig. 1b, a schematic thin-section is drawn for a situation at a certain depth corresponding to the reaction region (indicated with the horizontal dash line). Neglecting tectonic deformation, the pressure at the grain-grain interface (black spot in Fig. 1b) has to be equal to the lithostatic pressure (black spot in Fig. 1a) in order to support the weight of the overlying rocks. In other words, this situation at the fluid-saturated grain-grain interface is due to the necessity to maintain force balance across the interface so that the rock does not collapse (Robin, 1978; Rutter, 1983; Gratier, 2013). However, if fluid flow is sufficiently fast to equalize fluid pressure, the pressure in pores (red spot in Fig. 1b) follows the hydrostatic fluid pressure gradient (the blue line in Fig. 1a). Therefore, in the case of a metamorphic rock in which flow is sufficiently fast to establish a hydrostatic pressure gradient, fluid pressure is not equal to the lithostatic pressure in some parts of the reaction region. This results in a grain-scale variation between the fluid pressure in open pores $\left(P_{f}=\right.$ hydrostatic) and the fluid pressure at grain-grain interface $\left(P_{f}=\right.$ lithostatic). Such a fluid pressure variation will be 
maintained on the compaction time scale due to force balance. The above conceptual descriptions are in agreement with studies on pressure solution. It has been found that a thin (hundred $\mathrm{nm}$ scale) porous layer between grain-grain interface can remain fluid saturated during metamorphism (Gratier et al., 2013). The pressure difference between the fluid saturated thin layer and open pores has been recognized as the driving force responsible for dissolution-precipitation creep (Robin, 1978; Passchier \& Trouw, 1998 p. 26; Bernabe \& Evans, 2007).

Here, we chose garnet as a representative mineral to investigate the effect of grainscale pressure variation on prograde zoning and growth of a metamorphic mineral because it has been extensively recognized as a fractionated phase to determine the pressure-temperature $(P-T)$ history in metamorphic rocks (e.g. Tracy \& Robinson, 1976; Cygan \& Lasaga, 1982; Spear et al., 1991). We develop a numerical model based on the Perple_X computer program package (Connolly, 2009) described in the following chapter. Matlab ${ }^{\circledR}$ codes in combination with the Perple_X equilibrium thermodynamic solver are used to allow for pressure variation around the fractionating garnet during a prograde path up to $650{ }^{\circ} \mathrm{C}$. We quantify the magnitude of pressure variations from equilibrium thermodynamic calculations and investigate the effect on garnet growth and chemical zoning. The results show that the local deviations from isobaric conditions can be responsible for the development of asymmetric chemical zoning.

\section{MODEL DESCRIPTION}

The model of Vrijmoed \& Hacker (2014) is extended here to include pressure variation as an additional parameter. The model is separated into two parts: (1) a forward model part to calculate the chemical profile for a given prograde $P-T$ path at a fixed magnitude of pressure variation, and (2) an optimization part to determine the best fit $P-T$ path and the magnitude of pressure variation for a given rock. As the prograde $P-T$ path is placed at relatively low temperature condition $\left(<650^{\circ} \mathrm{C}\right)$ no 
chemical diffusion is considered within garnet. Based on experimental and numerical works, diffusion of chemical components along fluid saturated grain boundaries around a growing mineral can be as fast as in bulk water or ca. one or two orders of magnitude slower (Dysthe et al., 2002; Alcantar et al., 2003; Gratier et al., 2013). Therefore, in this model, we consider that the chemical homogenization along grain boundaries and/or interconnected porosity in the matrix (Fig. 1b) is achieved rapidly.

\section{Garnet growth along a $\boldsymbol{P}-\boldsymbol{T}$ path - A forward model}

The pressure variation around a growing garnet is simplified as a sinusoidal function shown in (Fig. 2a). At each point along the $P-T$ path, the garnet rim is discretized into cells (Fig. 2b) in which Gibbs free energy minimization using Perple_X (Connolly, 2009) is performed to retrieve local garnet composition and modal proportion from a common effective bulk composition, at constant temperature, and different pressure within each cell.

The garnet equilibrium volume calculated in individual cells is converted to $2 \mathrm{D}$ sectorial area and attached to the surface of the garnet rim (Fig. 2b, and Appendix S1). Following the model setup, the garnet volume difference among cells is a result of the local fluid pressure variation. The composition calculated for each cell is scaled based on its weight percentage, summed up, and fractionated from the bulk composition for the calculation of the next step. Afterwards the rock moves to the next $P-T$ point with fixed $\mathrm{P}-\mathrm{T}$ increment along the path using the fractionated bulk composition for all the cells until the final $P-T$ conditions are reached (Fig. 2c). To investigate the first order effect of the pressure variation, its magnitude is assumed to be constant along the $P-T$ path. More detailed description of the numerical model is provided in Appendix S1 and the effect of $P-T$ increment along the $P-T$ path is provided in Discussions and Implications. A benchmark of the forward model is given in Appendix S2.

The test example in Fig. 2b is computed using a pelitic bulk composition and a typical prograde $P-T$ path from Russo et al. (2006) under 0.5 kbar maximum pressure 
variation around the garnet. The significant asymmetry of the garnet shape and chemical zoning pattern demonstrate the potential importance of grain-scale pressure variation on garnet growth (see the development of asymmetry in Fig. 2b). The method to estimate the magnitude of maximum pressure variation is described in the following section.

\section{Optimization of the $\boldsymbol{P}-\boldsymbol{T}$ path and pressure variation (Pvar)}

An inverse modelling technique based on a brute-force search method (Vrijmoed \& Hacker, 2014) is used to obtain the best fit $P-T-P v a r$ conditions to the measured natural garnet zoning profiles. The peak $P-T$ conditions can be constrained with phase equilibria modelling and geothermobarometry using as a first guess the averaged garnet rim composition in order to estimate the peak $P-T$ conditions for further garnet growth modelling. The starting $P-T$ conditions and the pressure variation are constrained and meshed on 3-D coordinates for a fixed P-T increment (Fig. 3a). These three independent variables, i.e. the starting pressure, starting temperature and the amplitude of pressure variation, are independently varied to find the best fit $P-T-$ Pvar conditions (Fig. 3a). The garnet zoning profile is first calculated from one of the $P-T-P$ var conditions using the forward model described earlier. The zoning profile is subsequently compared to the measured profile to quantify the residual (Fig. 3b). For this purpose, the garnet modal volume is normalized to the grain size of the measured garnet profile. The individual residual for each end-member component can be quantified. The method to quantify the residual is described in Vrijmoed \& Hacker (2014) and illustrated in Fig. 3b. After evaluating the residual for individual end member components, the total residual is summed using the individual residual from all the four end members. Subsequently, the starting $P-T-P v a r$ point is moved over to the next grid and the same procedure is repeated (Fig. 3a). 


\section{MAGNITUDE OF THE PRESSURE VARIATION FOR ASYMMETRIC} GARNETS

Three representative asymmetrically zoned garnets have been collected from the literature to investigate the magnitude of the pressure variation.

\section{Description of selected samples}

The first sample, SR123, is a Ca-poor micaschist in Aspromonte Massif (southern Calabria, Italy; Russo et al., 2006). The second sample, OF2512, is an ultra-high pressure rock (Groppo et al., 2009) collected from Lago di Cignana (Western Alps containing coesite-eclogite facies. The third sample, TRE 1, is a blueschist from Ile de Groix (Armorican Massif, France; Ballevre et al., 2003). Bulk compositions of these samples are provided in Figure 4 together with isochemical phase-diagram sections. The phase-diagram sections are calculated with the Gibbs energy minimization Perple_X software package (Connolly, 2009) using the thermodynamic database of Holland \& Powell (1998, as revised in 2003). The solid solution models used in the calculation are indicated in Table $1 . \mathrm{H}_{2} \mathrm{O}$ is set to be $15 \%$ for SR123, OF2512, and $10 \%$ for TRE 1 to ensure fluid saturation. Moreover, the bulk composition of sample TRE 1 is recalculated using individual mineral's modal percent and composition, because the originally provided bulk composition does not incorporate the garnet core (no $\mathrm{MnO}$ considered). In the TRE 1 sample, the MnO composition is effectively zero in the garnet rim but relatively high in the garnet core. Therefore, it is assumed here that half of the garnet radius is composed of the core composition and the other half has the rim composition to incorporate the $\mathrm{MnO}$ content included in the garnet core.

For sample SR123 (Russo et al., 2006), the recalculated isochemical phase-diagram section is comparable to the original published one in Russo et al. (2006). The peak temperature for SR 123 is slightly modified by $15^{\circ} \mathrm{C}$ by systematic testing of different peak temperatures to find the one that fits the garnet rim. The new phase-diagram section for sample OF2512 is similar for most of the phases, such as lawsonite, garnet, 
coesite, omphacite and phengite. The biotite stability field is different. In the original phase diagram section, biotite is stable in the high pressure, low temperature and low pressure, higher temperature region whereas in the new calculation it is only restricted to low pressure $(<20 \mathrm{kbar})$, and high temperature zone $\left(<650^{\circ} \mathrm{C}\right)$. This discrepancy is related to different default settings in the older release of the Perple_X package. One of the program option parameters called "site-check" was previously set to "false" as default to allow negative site fractions. In the new version, the default setting is site check "true" to reject unrealistic negative site fractions (see details in http://www.perplex.ethz.ch/perplex options.html). For sample TRE 1, Ballevre et al., (2003) computed the bulk composition by neglecting the garnet core that is rich in $\mathrm{MnO}$ in order to perform phase diagram section calculation. In our model, we compute the whole rock chemistry including garnet core to perform garnet growth model along a $P-T$ path with fractionation. Therefore, the new phase diagram section is different from the $\mathrm{MnO}$ absent model in Ballevre et al., (2003). The major difference is that garnet becomes stable in the entire isochemical phase-diagram section but the topologies of the other major phase fields remain the same. The chlorite stability field is extended to higher pressures and temperatures. The peak temperature for sample TRE 1 estimated by Ballevre et al. (2003) at $450^{\circ} \mathrm{C}$ lies in the lawsonite stability field. However, the calculated garnet zoning profiles for the newly derived bulk rock composition do not fit the measured profiles using this peak temperature. According to the new phase diagram section, garnet continues to grow along the clockwise $P-T$ path suggested in Ballevre et al. (2003) beyond the lawsonite stability field. Therefore, the new peak temperature for sample TRE 1 deviates from $450^{\circ} \mathrm{C}$ by $85^{\circ} \mathrm{C}$ to reach the composition of the garnet's outermost rim by systematic testing of different peak temperatures. This temperature shift is also potentially induced by the aforementioned change in bulk chemistry as the uncertainty originated from the change of the bulk composition can be significant (Palin et al., 2015). 


\section{Results}

The calculated results for the three selected samples are illustrated in Figures 5, 6, 7. Only the total residual map slices (grossular + almandine + spessartine + pyrope) are portrayed as they represent the comprehensive fitting residual for all the four end members. The figure setup resembles the grid discretization shown in Figure 3a (note that the temperature coordinate is reversed to visualize the minimal error).

The residual map slices are arranged as (1) zero magnitude of pressure variation (isobaric); (2) the best fit magnitude of pressure variation, and (3) the doubled best fit magnitude of pressure variation (Fig. 5a, 6a, 7a). The best fit $P-T$ path always lie in the middle slice with non-zero Pvar, indicating that an improvement of the quality of the $P-T$ path can be achieved with the prescribed grain-scale pressure variation. The best fit $P-T$ conditions are labeled on each residual map slices. The position of the best fit $P-T$ conditions vary slightly as the magnitude of pressure variation changes.

The 2-D garnet element map using the best fit $P-T-P v a r$ conditions are calculated (Fig. 5d, 6d, 7d). The calculated profiles with the best-fit magnitude pressure variation (black lines) are illustrated individually and compared with the extracted measured profile (blue dots; Fig. 5d, 6d, 7d). The direction of the extracted profile is always parallel to the long axis of the grain, as it represents the highest asymmetry (see truncated horizontal profile A-B in Fig. 2). The calculated profiles assuming no pressure variation are characterized by the green dashed curves (Fig. 5d, 6d, 7d), to show the difference caused by pressure variation.

The best fit $P-T-P$ var conditions are tabulated in Table 1 for all the samples together with the calculated and the observed garnet volume percentage. Different samples reveal different magnitude of pressure variation depending on the asymmetry of the zoning profile and the bulk composition.

\section{DISCUSSIONS AND IMPLICATIONS}

The primary aim is to investigate the effect of grain-scale pressure variation on a 
260

261

262

263

264

265

266

267

268

269

270

271

272

273

274

275

276

277

278

279

280

281

282

283

284

285

286

growing metamorphic mineral, taking garnet as an example. Results from the numerical model document that the effect of grain-scale pressure variation may be responsible for the development of the asymmetric chemical zoning. Asymmetrically zoned garnets are commonly observed in metamorphic rocks but are mostly measured along the chemically symmetric half of the profile or simply not considered. However, several models explaining the garnet asymmetry were proposed: 1) plastic deformation or brittle fracturing of garnet (Azor et al., 1997; Storey \& Prior, 2005; Kim, 2006; Terry \& Heidelbach, 2006; Bestmann et al., 2008; Floess \& Baumgartner, 2013); 2) sluggish chemical diffusion in garnet (Wilbur \& Ague, 2006; Carlson et al., 2015); 3) garnet grains impingement and annealing (Whitney \& Seaton, 2010); 4) heterogeneous chemical distribution around a growing garnet due to a limited mass transport in the matrix (O'Brien, 1999; Bruno \& Rubbo, 2006). This scenario has been suggested to be likely considering the implication of sluggish chemical diffusion of rate controlling ion $\left(\mathrm{Al}^{3+}\right)$ in a corona structure (Carlson, 2010). If there is no observational evidence that any of the above mentioned models can be applied and when mass transport in the matrix and grain boundaries is fast, pressure variation may be a possible explanation for the asymmetric chemical zoning in garnet.

The constrained pressure variation provides an indication on how much the system pressure can deviate from the isobaric conditions to produce the asymmetric zoning assuming that asymmetric chemical zoning is entirely due to this pressure gradient. The simulations provide insight into the quality of the $P-T$ path estimates and the role of the $P-T$ increment during the garnet fractionation. The pressure variation amplitude can influence the relative position of garnet core and thus provide more realistic calculated zoning profile when compared to petrographic observations. Specific issues about the magnitude, effect and further implications of pressure variation, as well as the limitation of the numerical approach are discussed below. 


\section{Implications for thermobarometric estimates}

288 The prescribed magnitude of pressure variation has an influence on the best fit $P-T$ 289 path for the asymmetrically zoned garnet. Such influence can be large, as in sample 290 TRE 1 (9 kbar and $50{ }^{\circ} \mathrm{C}$ for the starting point; Fig. 7a), or small, as in sample SR123 and OF2512 (about $1 \mathrm{kbar}$ and $10{ }^{\circ} \mathrm{C}$; Fig. 5a, 6a, respectively). Note that in sample TRE 1, two plausible $P-T$ regions with low fitting residual are found for each magnitude of pressure variation (the red regions of low fitting residual in Figure 7a). One of the low residual regions, which has smaller residual at 0 kbar of pressure variation, vanishes as the magnitude of pressure variation increase, whereas the other low residual region gradually decreases in its residual and eventually provides the best fit $P-T$ path (Fig. 7a). Without introducing pressure variation, the first low residual region will be accepted as the most plausible one. The validity of our garnet model is supported by the petrological observation in Ballevre et al. (2003) where amphibole and epidote inclusions are trapped in garnet grains as predicted from the $P-T$ section along the $P-T$ path involving the pressure variation (Fig. 4c). No amphibole or epidote is found along the $P-T$ path if the magnitude of pressure variation is taken as zero (see Fig. 4c, 7). This suggests that the phases crossed along a linear $P-T$ path simulated with pressure variation fits the actual observation better than the modelled ones without pressure variation.

The deviation in the $P-T$ space caused by the pressure variation may be significant if the garnet is more asymmetric than the provided examples. When the pressure variation is higher, the equilibrium garnet volume fraction and end member proportion in each cell also vary which influences the best fit starting $P-T$ conditions. Therefore, an improved starting $P-T$ condition can be found with the prescribed pressure variation, assuming that other factors, such as sluggish kinetics, surface energy, local chemical equilibrium, do not significantly influence the garnet asymmetry. 


\section{The sensitivity of modelling to the chosen $P-T$ increment}

316 The asymmetry of garnet chemical zoning in the model is subject to the $P-T$ 317 increment along the $P-T$ path as illustrated in Fig. 8. When the $P-T$ path first hits the 318 initial garnet entry isopleth, the garnet nucleus grows and the bulk composition is 319 fractionated, causing the garnet entry boundary to migrate to higher $P-T$ conditions. 320 For the $P-T$ conditions of the next increment on the path two extreme end members 321 can be envisaged. (1) If we consider an extremely small $P-T$ increment, for a fixed 322 non-zero magnitude of pressure variation, only part of the garnet would touch the 323 entry isopleth at the next equilibrium condition (Fig. 8b). In the applied model, this 324 would predict large asymmetry even at small magnitude of pressure variation. (2) 325 Contrarily, if we assumed a large $P-T$ increment, more symmetrically shaped garnet would grow under the same magnitude of pressure variation because the pressure around the entire garnet would lie in the garnet stability field (Fig. 8c).

328

The model garnet asymmetry is quantified using the radius ratio which is defined as the ratio of the maximum and minimum distance to the core in a bilateral bisection through the grain (see the illustration of a zoned garnet profile in Fig. 9a). The radius ratio of the measured profile is set as an input, and serves to distinguish how asymmetric the garnet is. The radius ratio of the modeled zoning profiles is plotted as contours in Fig. 9, where the radius ratio of the measured garnet profile is represented by the thick black contour. The black contour represents the situation where the measured and the calculated zoning profiles match each other in terms of their geometrical asymmetry. This radius ratio of the modeled profiles can be kept constant while the magnitude of pressure variation and $P-T$ increment is varied (see contours in Fig. 9).

Based on Fig. 9, the magnitude of pressure variation that gives the best fit converges to a small but non-zero value when the $P-T$ increment is sufficiently small (high resolution in Fig. 9). For a $T$ increment above $10 \sim 15^{\circ} \mathrm{C}$, the required magnitude of pressure variation is large. An estimate of minimal $5^{\circ} \mathrm{C} T$ increment corresponds to a 
magnitude of pressure variation ranging from 1.5 to 9 kbar depending on the specific sample as illustrated in Fig. 9. The choice of the $P-T$ increment is partly constrained by the measured data because a sufficiently discretized $P-T$ path is needed to obtain a reasonable fit. However, it may correspond to a range of possible pressure variations as shown in Fig. 9 (the blue low residual region), instead of a unique value. Thus, this examined range of the magnitude of pressure variation is geologically relevant if it provides a satisfactory fit between the measured and calculated garnet zoning profiles (i.e. if the lowest residuals in that range are acceptable). The best-fit magnitudes of pressure variation determined from Fig. 5-7 fall into this range, which represents the actual possible deviation from isobaric conditions that can be potentially used to interpret the metamorphic conditions.

\section{Pressure variation during prograde mineral growth}

The proposed model is applicable in the case where fluid pressure variation exists during growth of the fractionating mineral (i.e. garnet) along the prograde path. Below, three possibilities relevant to the presence of fluid pressure variations are discussed.

\section{1) Hydrostatic fluid in a metamorphic reaction region}

Etheridge et al. (1983) suggested that many low and medium metamorphic regions involve large-scale fluid circulations. This implies an interconnected porosity that allows porous flow to establish a hydrostatic fluid pressure gradient. The difference between the hydrostatic and lithostatic pressure gradient resulting from the density difference of fluid and solid and assuming no tectonic deformation implies that grain scale fluid pressure varies between lithostatic and hydrostatic pressure (see Introduction and Fig. 1). Although the fluid saturated grain boundaries have thicknesses on the nanometer scale, diffusion speed in such grain boundaries is sufficiently high to transport material efficiently around the grain (Gratier et al. 2013 section $3.1 \mathrm{pp}$. 96). This is supported by pressure solution experiments in which the transport of dissolved material proceeds from the high fluid pressure in the thin film 
371 to the low pressure side of the grain where it precipitates (De Boer et. al., 1977; Rutter, 372 1983).

373 2) Fluid saturated solids under stress

374 Under low permeability conditions, large-scale fluid circulations may be unlikely and 375 the pressure in the fluid may approach lithostatic pressure as summarized in Yardley 376 \& Bodnar, 2014 (section 3.3 \& 4.2 p. 86). However, heterogeneous solids under stress 377 generally give rise to heterogeneous stress and pressure distribution. Well understood examples are spherical viscous inclusions undergoing shear in a higher- or lower viscosity matrix (Schmid \& Podladchikov 2003; Moulas et al, 2014). More complex microstructures and mineralogy lead to more heterogeneous stresses and the pressure in this case does not necessarily show a simple and regular pattern (i.e. Wheeler, 1987, Tajčmanová et al, 2015).

The pressure of a fluid present at any time in the pores of the matrix or at grain boundaries has to equal the local normal stress of the solid in order to maintain force balance. Therefore, as long as the rock is under stress, fluid pressure variation resulting from the force balance between fluid and solid is maintained. Therefore, the magnitude and duration of fluid pressure variation is closely connected to stress levels and relaxation of the solid. Depending on the viscosity of the matrix and the strain rate, this may vary on the kbar level and be maintained on geological time scales which has been documented by recent studies (Moulas et al., 2014; Tajčmanová et al., 2015, Dabrowski et al., 2015)

\section{3) Reactive transport}

In a reactive system where a fluid phase is involved, fluid overpressure/ underpressure can be generated by (de)-hydration reactions in compact metamorphic rocks (Connolly, 1997). The fluid pressure evolution is mutually related to the speed of metamorphic reactions. If fluid pressure locally generated by the reaction is faster than the relaxation by flow, a significant pressure variation may develop during the metamorphic reaction. Such a competition between devolatilization generated fluid 
pressure and relaxation by flow has been studied thoroughly by Aarnes et al., (2012). Moreover, several recent studies pointed out that the metamorphic reaction may occur over shorter duration than previously anticipated, from the order of 10 years to a few thousand years (Camacho et al., 2005; Ague \& Baxter, 2007; John et al., 2012). Very rapid garnet growth up to c. $80 \mathrm{~mm}^{3}$ per thousand years is also measured using the $\mathrm{Sm}-\mathrm{Nd}$ dating method that is potentially related to episodic fluid flow pulse (Pollington \& Baxter, 2010). In the theoretical and numerical models on reactive transport and fluid flow (e.g. Steefel et al, 2005), chemical reactions are considered to occur immediately during fluid flow. Therefore, a fluid pressure gradient must exist during the reaction in order to drive the fluid flow. Moreover, if the reaction rate is fast, it may provide enough time for mineral growth to record the pressure variations even if it grew in a mechanically dynamic and reactive environment.

\section{Model limitation and concluding remarks}

1. The $P-T$ path is assumed to be linear. This is a first order approximation for the real prograde $P-T$ conditions. However, the real $P-T$ path can be arbitrarily curved. Similarly, the magnitude of pressure variation may also vary along the $P-T$ path.

2. The magnitude of fluid pressure variation is assumed to be a constant. In nature, it is not likely that the fluid pressure variation is maintained exactly the same over geological time. The magnitude and spatial distribution of fluid pressure may be subject to the chemical reaction, and mechanical environment around the garnet. It is recognized that an increase of temperature in prograde metamorphism will reduce the viscosity, thus further changes the pressure variation (see Fig. 1).

3. Fractionation of other phases may also need to be taken into consideration because zoning has also been frequently observed in, e.g. plagioclase etc. This should be carefully treated when other zoned minerals are observed in the sample.

4. Crystal size distribution (CSD; e.g. Higgins, 2000; Carlson, 2002; Ketcham \& 
Carlson, 2012) is not considered here due to a lack of CSD statistics in garnet zoning literature. Only one garnet is assumed to grow in the given system, and it is equivalent to multiple garnets model with same radius in terms of the shape of the chemical zoning profile.

5. Diffusion in the fractionating crystal is not considered in the present model. The model covers relatively low temperature region (below $600^{\circ} \mathrm{C}$ ) where the influence of diffusion is supposed to be minor as documented by other models (Ague \& Baxter, 2007; Gaidies et al., 2008 a, b; Caddick et al., 2010).

6. The outcome of the model, estimated $P-T$ path and magnitude of pressure variation are subject to the choice of database and solid solution model. Careful consideration must be made prior to the implementation of the thermodynamic model on the garnet model discussed before.

7. Sluggish kinetics is not considered due to the assumption of complete equilibrium in the matrix. The free variables in our model are pressure, temperature, and the magnitude of pressure variation.

The model limitations, e.g. a linear $P-T$ path, may potentially lead to mismatch between the computed zoning profile and the measured ones, such as the opposite polarity of the grossular zoning profile shown in Fig. 5d. Better match can be achieved by adding more variations, such as $P-T$ path curvature, crystal size distribution, or even garnet absorption during a retrograde metamorphism after prograde garnet growth. However, these additions would not generate any asymmetry in the zoning. The purpose of this study is to provide an alternative to explain the asymmetrically zoned garnet using only the local pressure variation. This may inspire to reconsider the interpretation of the modeled $P-T$ path determined by classical petrology approaches and also to generally re-evaluate the asymmetrically zoned minerals. The assumption of isobaric pressure around the garnet rim may potentially lead to an inaccurately estimated $P-T$ path. A consideration of the entire chemically zoned profile provides not only a better estimate of $P-T$ path but also an important 
454 estimate of the magnitude of pressure variation on both side of the asymmetrically 455 zoned garnet. Therefore, both quantification approaches - the classical isobaric and 456 the polybaric alternative - may need to be equally considered in petrographic 457 observations.

458

459

460

461

462

463

464

465

\section{ACKNOWLEDGEMENTS}

The authors address special thanks to Pierre Lanari, Mark Caddick, Roger Powell, and other two anonymous reviewers for their careful reviews and insightful suggestions that greatly improve the quality of the work. The authors sincerely thank Michael Brown for his editorial work. The authors are greatly indebted to Evangelos Moulas and Yuri Podladchikov for carefully reading the manuscript and providing valuable suggestions. The authors thank Taras Gerya and James Connolly for helpful discussions and critical questions on this model. Xin Zhong thank Julian Storck and Linwei $\mathrm{Hu}$ for providing feedback of the Introduction part. This work was supported by MADE-IN-EARTH ERC starting grant (n. 335577).

\section{REFERENCES}

Ague, J.J., \& Baxter, E.F., 2007. Brief thermal pulses during mountain building recorded by $\mathrm{Sr}$-diffusion in apatite and multicomponent diffusion in garnet. Earth and Planetary Science Letters. 261, 500-516.

Alcantar, N., Israelachvili, J., \& Boles, J. 2003. Forces and ionic transport between mica surfaces: Implications for pressure solution. Geochimica et Cosmochimica Acta. 67:1289-1304.

Angel, R.J., Nimis, P., Mazzucchelli, M.L., Alvaro, M., \& Nestola, F., 2015. How large are departures from lithostatic pressure? Constraints from host-inclusion elasticity. Journal of Metamorphic Geology. 33(8):801-813. 
480

481

482

483

484

485

486

487

488

489

490

491

492

493

494

495

496

497

498

499

500

501

502

503

504

505

506

Aarnes, I., Podladchikov, Y., \& Svensen, H., 2012. Devolatilization-induced pressure build-up: Implications forreaction front movement and breccia pipe formation. Geofluids. 12:265-279.

Azor, A., Simancas, J. F., Exposito, I., Lodeiro, F. G. \& Poyatos, D. J. M., 1997. Deformation of garnets in a low-grade shear zone. Journal of Structural Geology 19, 1137-1148.

Ballevre, M., Pitra, P. \& Bohn, M., 2003. Lawsonite growth in the epidote blueschists from the Ile de Groix (Armorican Massif, France): a potential geobarometer. Journal of Metamorphic Geology, 21, 723-735.

Bernabe, Y., \& Evans, B., 2007. Numerical modelling of pressure solution deformation at axisymmetric asperities under normal load. Geological Society, London, Special Publications. 1: 185-205.

Bestmann, M., Habler, G., Heidelbach, F., \& Thöni, M. 2008. Dynamic recrystallization of garnet and related diffusion processes. Journal of Structural Geology, 30(6), 777-790.

Bruno, M. \& Rubbo, M., 2006. The metamorphic history of Monte Mucrone metagranodiorite constrained by garnet growth modelling. Periodico Di Mineralogia, $75,3-22$.

Camacho, A., Lee, J.K.W., Hensen, B.J., \& Braun, J., 2005. Short-lived orogenic cycles and the eclogitization of cold crust by spasmodic hot fluids. Nature. 435:11911196.

Caddick, M.J., Konopasek, J., \& Thompson, A.B., 2010. Preservation of Garnet Growth Zoning and the Duration of Prograde Metamorphism. Journal of Petrology, 51, 2327-2347.

Carlson, W. D. 2002. Presidential Address. Scales of disequilibrium and rates of equilibration during metamorphism. American Mineralogist, 87(263), 185-204.

Carlson, W.D., 2010. Dependence of reaction kinetics on $\mathrm{H} 2 \mathrm{O}$ activity as inferred 
507 from rates of intergranular diffusion of aluminium. Journal of Metamorphic Geology.

508

509

510

511

512

513

514

515

516

517

518

519

520

521

522

523

524

525

526

527

528

529

530

531

532

533

28: 735-752.

Carlson, W. D., Hixon, J.D., Garber, J. M. \& Bodnar, R. J., 2015. Controls on metamorphic equilibration: the importance of intergranular solubilities mediated by fluid composition. Journal of Metamorphic Geology, 33, 123-146.

Chen, K., Kunz, M., Tamura, N., \& Wenk, H.R., 2015. Residual stress preserved in quartz from the San Andreas Fault Observatory at Depth. Geology. 43: 219-222

Coggon, R., \& Holland, T.J.B., 2002. Mixing properties of phengitic micas and revised garnet-phengite thermobarometers. Journal of Metamorphic Geology. 20:683-696.

Connolly, J.A.D., 1997. Devolatilization-generated fluid pressure and deformationpropagated fluid flow during prograde regional metamorphism. Journal of Geophysical Research, 102, 18149-18173.

Connolly, J.A.D., 2009. The geodynamic equation of state: What and how. Geochemistry Geophysics Geosystems, 10, 10.

Connolly, J.A.D., 2010. The mechanics of metamorphic fluid expulsion. Elements. 6:165-172.

Connolly, J.A.D., Y.Y. Podladchikov. 2012. Chapter 14. A hydromechanical model for lower crustal fluid flow. D. Harlov, H. Austrheim (Eds.), Metasomatism and the Chemical Transformation of Rock: Rock-mineral-fluid Interaction in Terrestrial and Extraterrestrial Environments.

Cygan, R., \& Lasaga, A.C. 1982. Crystal growth and the formation of chemical zoning in garnets. Contributions to Mineralogy and Petrology. 79:187-200.

Dabrowski, M., Powell, \& R., Podladchikov, Y., 2015. Viscous relaxation of grainscale pressure variation. Journal of Metamorphic Geology. 33, 859-868

Dahlen, F. A., 1992. Metamorphism of Nonhydrostatically Stressed Rocks. American Journal of Science, 292, 184-198. 
534 Dale, J., Powell, R., White, R.W., Elmer, F.L., \& Holland, T.J.B. 2005. A 535 thermodynamic model for $\mathrm{Ca}-\mathrm{Na}$ clinoamphiboles in $\mathrm{Na} 2 \mathrm{O}-\mathrm{CaO}-\mathrm{FeO}-\mathrm{MgO}-$ 536 Al2O3-SiO2-H2O-O for petrological calculations. Journal of Metamorphic Geology. 537 23:771-791.

538 De Boer, R.B., Nagtegaal, P.J.C., \& Duyvis, E.M., 1977. Pressure solution 539 experiments on quartz sand. Geochimica et Cosmochimica Acta. 41: 257-264.

540 Dysthe, D.K., Renard, F., Porcheron, F., \& Rousseau, B. 2002. Fluid in mineral 541 interfaces - molecular simulations of structure and diffusion. Geophysical Research $542 \quad$ Letter, 29:1-4.

543 Etheridge, M.A., Wall, V.J., \& Vernon, V.J., 1983. The role of the fluid phase during 544 regional metamorphism and deformation. Journal of Metamorphic Geology. 1:205545226.

546 Floess, D. \& Baumgartner, L., 2013. Formation of garnet clusters during polyphase 547 metamorphism. Terra Nova, 25, 144-150.

548 Gaidies, F., de Capitani, C., \& Abart, R., 2008. THERIA_G: a software program to 549 numerically model prograde garnet growth. Contributions to Mineralogy and 550 Petrology, 155, 657-671.

551 Gaidies, F., de Capitani, C., Abart, R. \& Schuster, R., 2008. Prograde garnet growth 552 along complex $P-T-t$ paths: results from numerical experiments on polyphase garnet 553 from the Wolz Complex (Austroalpine basement). Contributions to Mineralogy and 554 Petrology, 155, 673-688.

555 Gibbs, J.W., 1876. On the equilibrium of heterogeneous substances. Transactions of 556 the Connecticut Academy. 3:108-248.

557 Gratier, J.P., Dysthe, D. \& Renard, F. 2013. The role of pressure solution creep in the 558 ductility of the earth's upper crust. Advances in Geophysics, 54:47-179.

559 Groppo, C., Beltrando, M. \& Compagnoni, R., 2009. The $P-T$ path of the ultra-high 560 pressure Lago Di Cignana and adjoining high-pressure meta-ophiolitic units: insights 
561 into the evolution of the subducting Tethyan slab. Journal of Metamorphic Geology, $562 \quad 27,207-231$.

563 Higgins, M. D. 2000. Measurement of crystal size distributions. American 564 Mineralogist, 85(869), 1105-1116.

565 Hobbs, B., \& Ord, A., 2015. Forum Comment: Dramatic effects of stress on 566 metamorphic reaction. Geology. 43:e372; doi:10.1130/G37070C.1.

567 Holland, T. J. B. \& Powell, R., 1998. An internally consistent thermodynamic data set 568 for phases of petrological interest. Journal of Metamorphic Geology, 16, 309-343.

569 John, T., Gussone, N., Podladchikov, Y.Y., Bebout, G.E., Dohmen, R., Halama, R., 570 Klemd, R., Magna, T., \& Seitz, H.M. 2012. Volcanic arcs fed by rapid pulsed fluid 571 flowthrough subducting slabs. Nature Geoscience. 5:489-492.

572 Ketcham, R.A. \& Carlson W.D. 2012. Numerical simulation of diffusion-controlled 573 nucleation and growth of porphyroblasts. Journal of Metamorphic Geology. 30:489574512.

575 Kim, H. S., 2006. Deformation-induced garnet zoning. Gondwana Research, 10, $576 \quad 379-388$.

577 Llana-Funez, S., Wheeler, J. \& Faulkner, D. R., 2012. Metamorphic reaction rate 578 controlled by fluid pressure not confining pressure: implications of dehydration 579 experiments with gypsum. Contributions to Mineralogy and Petrology, 164, 69-79.

580 Mancktelow, N. 1993. Tectonic overpressure in competent mafic layers and the 581 development of isolated eclogites. Journal of Metamorphic Geology. 11: 801-812

582 Moulas, E., Burg, J. P. \& Podladchikov, Y., 2014. Stress field associated with elliptical 583 inclusions in a deforming matrix: Mathematical model and implications for tectonic 584 overpressure in the lithosphere. Tectonophysics, 631, 37-49.

585 Moulas, E., Tajčmanová, L., Vrijmoed, J.C., \& Podladchikov, Y.Y., 2015, 586 Mechanically-v. diffusion-controlled metamorphic microstructure: a symplectite 
example from Rhodope Metamorphic Complex (Greece), Journal of Metamorphic Geology. doi:10.1111/jmg.12141.

Nasdala, L., Hofmeister, W., Harris, J.W., Glinnemann, J., 2005. Growth zoning and strain patterns inside diamond crystals as revealed by Raman maps. American Mineralogist. 90, 745-748.

Newton, R.C., Charlu, T.V., \& Kleppa, O.J., 1980. Thermochemistry of the high structural state plagiocalses. Geochimica et Cosmochimica Acta. 44:933-941.

O'Brien, P. J., 1999. Asymmetric zoning profiles in garnet from HP-HT granulite and implications for volume and grain-boundary diffusion. Mineralogical Magazine, 63, $227-238$.

Palin, R.M., Weller, W.M., Waters, D.J., \& Dyck, B., 2015. Quantifying geological uncertainty in metamorphic phase equilibria modelling; a Monte Carlo assessment and implications for tectonic interpretations. Geoscience Frontiers. In press.

Passchier, C.W., \& Trouw, R.A.J., 1998. Microtectonics. Springer-Verlag, Berlin.

Petrini, K., \& Podladchikov, Y. 2000. Lithospheric pressure-depth relationship in compressive regions of thickened crust. Journal of Metamorphic Geology. 18:67-77.

Pollington, A., \& Baxter, E., 2010. High resolution Sm-Nd garnet geochronology reveals the uneven pace of tectonometamorphic processes. Earth and Planetary Science Letters. 293:63-71.

Robin, P.Y., 1978. Pressure solution at grain-to-grain contacts. Geochimica et Cosmochimica Acta. 42:1383-1389.

Russo, S., Cutrupia, D., Bella, M.D \& Minutoli, C., 2006. High-pressure metamorphism in southern Calabria, Italy: the Cardeto chlorite-garnet metapelites. Periodico Di Mineralogia, 75, 23-42.

Rutter, E.H., 1983. Pressure solution in nature, theory and experiment. Journal of Geological Society London. 140: 725-740. 
613 Schmid, D.W, Podladchikov Y.Y., 2003. Analytical solutions for deformable elliptical 614 inclusions in general shear. Geophysical Journal International. 155:269-288.

615 Spear, F.S., 1993. Metamorphic phase euilibria and pressure-temperature-time path. 616 Mineralogical Society of America Monograph. New York. U.S.A.

617 Spear, F. S., Kohn, M. J., Florence, F. P. \& Menard, T., 1991. A model for garnet and 618 plagioclase growth in pelitic schists: implications for thermobarometry and $P-T$ path 619 determinations. Journal of Metamorphic Geology, 8, 683-696.

620 Steefel, C., DePaolo, D.J., \& Lichtner, P., 2005. Reactive transport modeling: An 621 essential tool anda new research approach for the Earth sciences. Earth and Planetary 622 Science Letters. 240:539-558.

623 Storey, C. D., \& Prior, D. J. 2005. Plastic deformation and recrystallization of garnet: 624 a mechanism to facilitate diffusion creep. Journal of Petrology, 46(12), 2593-2613.

625 Tajčmanová, L., Connolly, J.A.D., \& Cesare, B., 2009. A thermodynamic model for 626 titanium and ferric iron solution in biotite. Journal of Metamorphic Geology. 27:153627165.

628

629

630

631

632 633

634

635

636

637

638

639
Tajčmanová, L., Podladchikov, Y., Powell, R., Moulas E., Vrijmoed, J. C. \& Connolly J.A.D., 2014. Grain-scale pressure variations and chemical equilibrium in high-grade metamorphic rocks. Journal of Metamorphic Geology, 32, 195-207.

Tajčmanová, L., Vrijmoed, J. C. \& Moulas, E., 2015. Grain-scale pressure variations in metamorphic rocks: implications for the interpretation of petrographic observations. Lithos, 216-217, 338-351.

Terry, M. P. \& Heidelbach, F., 2006. Deformation-enhanced metamorphic reactions and the rheology of high-pressure shear zones, Western Gneiss Region, Norway. Journal of Metamorphic Geology, 24, 349-349.

Thompson, J.B., \& Waldbaum, D.R., 1968. Mixing properties of sanidine crystalline solutions: I Calculations based on ion-exchange data. The American Mineralogist. 53:1965-1999. 
640 Tracy, R. J., Robinson, P. \& Thompson, A. B., 1976. Garnet Composition and Zoning 641 in Determination of Temperature and Pressure of Metamorphism, Central 642 Massachusetts. American Mineralogist, 61, 762-775.

643 Vrijmoed, J. C. \& Hacker, B. R., 2014. Determining $P-T$ paths from garnet zoning 644 using a brute-force computational method. Contributions to Mineralogy and 645 Petrology, 167, 997.

646 Wheeler, J., 1987. The Significance of Grain-Scale Stresses in the Kinetics of 647 Metamorphism. Contributions to Mineralogy and Petrology 97(3): 397-404.

648 Whitney, D.L., \& Evans, B.W., 2010. Abbreviations for names of rock-forming 649 minerals. American Mineralogist, 95, 185-187.

650 Whitney, D. L. \& Seaton, N. C. A., 2010. Garnet polycrystals and the significance of 651 clustered crystallization. Contributions to Mineralogy and Petrology, 160, 591-607.

652 Wilbur, D. E. \& Ague, J. J., 2006. Chemical disequilibrium during garnet growth: 653 Monte Carlo simulations of natural crystal morphologies. Geology, 34, 689-692.

654 Winter, J.D., 2010. Principle of Igneous and Metamorphic Petrology. Upper Saddle 655 River, N.J. Prentice Hall.

656 Yardley, B.W.D. and Bodnar, R.J. 2014. Fluid in the Continental Crust. Geochemical 657 Perspectives. 3(1).

658 Zhang, Y., 1998. Mechanical and phase equilibria in inclusion-host systems. Earth 659 and Planetary Science Letter.157:209-222.

660 Zhong, X., Vrijmoed, J.C., Moulas, E., \& Tajčmanová, L. 2015. On coupling of 661 viscous relaxation and chemical diffusion under grain scale pressure variation. 662 Geotectonic Research. 97(1):106-107.

663 


\section{FIGURES AND TABLES}

665 Table 1: The model input data including solid solution models, $P-T$ paths of the 666 samples and model output including the best fit starting pressure, temperature, 667 pressure variation, and calculated garnet mode. Sources of solid solution models are 668 listed below the table.

\begin{tabular}{|c|c|c|c|}
\hline $\begin{array}{l}\text { Sample name } \\
\text { No. of Fig. } \\
\text { Reference }\end{array}$ & $\begin{array}{c}\text { SR123 } \\
5 \\
\text { Russo (2006) }\end{array}$ & $\begin{array}{c}\text { OF2512 } \\
6 \\
\text { Groppo } \\
(2009)\end{array}$ & $\begin{array}{c}\text { TRE } 1 \\
7 \\
\text { Ballevre } \\
\text { (2003) }\end{array}$ \\
\hline mineral solid solution phases & $\begin{array}{c}\text { garnet, } \\
\text { biotite, } \\
\text { chlorite, } \\
\text { feldspar, } \\
\text { muscovite, } \\
\text { cordierite, } \\
\text { staurolite, } \\
\text { amphibole }\end{array}$ & $\begin{array}{l}\text { garnet, } \\
\text { biotite, } \\
\text { chlorite, } \\
\text { feldspar, } \\
\text { muscovite, } \\
\text { omphacite, } \\
\text { cordierite, } \\
\text { amphibole, } \\
\text { phengite }\end{array}$ & $\begin{array}{c}\text { garnet, } \\
\text { biotite, } \\
\text { chlorite, } \\
\text { feldspar, } \\
\text { amphibole, } \\
\text { omphacite, } \\
\text { epidote }\end{array}$ \\
\hline Peak $P-T$ & $\begin{array}{l}10 \mathrm{kbar} \\
565^{\circ} \mathrm{C}\end{array}$ & $\begin{array}{l}32 \mathrm{kbar} \\
600^{\circ} \mathrm{C}\end{array}$ & $18 \mathrm{kbar}, 535^{\circ} \mathrm{C}$ \\
\hline$P-T$ search domain & $\begin{array}{l}3 \sim 10 \mathrm{kbar} \\
490 \sim 570^{\circ} \mathrm{C}\end{array}$ & $\begin{array}{l}10 \sim 30 \mathrm{kbar} \\
450 \sim 600^{\circ} \mathrm{C}\end{array}$ & $\begin{array}{l}3 \sim 18 \mathrm{kbar} \\
450 \sim 550^{\circ} \mathrm{C}\end{array}$ \\
\hline $\begin{array}{c}\text { Best fit } \\
P-T \text { point }\end{array}$ & $\begin{array}{l}3.6 \mathrm{kbar} \\
524^{\circ} \mathrm{C}\end{array}$ & $\begin{array}{l}9.3 \mathrm{kbar} \\
614^{\circ} \mathrm{C}\end{array}$ & $\begin{array}{l}5.2 \mathrm{kbar} \\
498^{\circ} \mathrm{C}\end{array}$ \\
\hline $\begin{array}{c}\text { Best fit } \\
\text { Pvar magnitude }\end{array}$ & $1 \mathrm{kbar}$ & $0.75 \mathrm{kbar}$ & $0.75 \mathrm{kbar}$ \\
\hline Calculated Grt mode (vol\%) & $1.65 \%$ & $22.1 \%$ & $16.5 \%$ \\
\hline Observed Grt mode (vol\%) & Not reported & Not reported & $\sim 15 \%$ \\
\hline
\end{tabular}

669 The garnet, chlorite, chloritoid and staurolite solution models are from Holland \& 
670 Powell (1998); biotite model is from (Tajčmanová et al., 2009); feldspar includes

671 plagioclase from (Newton et al., 1980), and K-feldspar from (Thompson \&

672 Waldraum 1968); amphibole model is from (Dale et al., 2005); muscovite is from

673 (Coggon \& Holland 2002).

674 
675 Fig. 1. (a) Schematic curves showing an example of the trends for fluid pressure 676 (denoted as $P_{f}$ ) in blue curve and lithostatic pressure (denoted as $P_{l}$ considering 677 both solid and fluid in a rock aggregate) in black line modified after Connolly, 2010 678 and Connolly \& Podladchikov, 2012. At depth, the fluid pressure first follows the 679 lithostatic pressure gradient (proportional to the rock density $\rho_{r}$ ) above the reaction 680 front. It is elevated at the reaction front due to devolatilization reactions. Within the 681 porous reaction region, the fluid pressure drops following the hydrostatic gradient 682 (proportional to fluid density $\rho_{f}$ ). Eventually the fluid pressure is elevated back to the 683 lithostatic pressure at the bottom of reaction region where significant compaction 684 occurs again. Therefore, the difference between fluid pressure and lithostatic pressure $685 \Delta P$ can vary in depth. (b) A zoomed-in grain-scale image at the depth indicated by the grey dash line assuming no tectonic deformation occurs. At this depth the fluid pressure is lower than the lithostatic pressure in (a). The depth scale is the same in (a) and (b). The width of grain-grain interface is exaggerated for illustration. The fluid pressure at the grain-grain interface (indicated by the black spot in (b)) has to be equal to the lithostatic pressure under no tectonic deformation (black spot in (a)) in order to maintain force balance in the direction perpendicular to the interface. Therefore, the pressure in open pores and at grain-grain interface are not equal to each other except at the depth where the fluid pressure and the lithostatic pressure overlap each other. At the depth of the grey dash line, the difference between the pressure in open pores and at grain-grain interface is $\Delta P$ characterized by the horizontal bracket in (a).

Fig. 2: (a) Local pressure variation as a function of orientation in degree. The pressure distribution is simplified as a sinusoidal function to capture the pressure variation. (b) A calculation using the pressure distribution shown in (a). The garnet starts to grow from a nuclei stage (I). The pressure is higher on the left and lower on the right side of the garnet. An asymmetrically zoned garnet is grown after the accumulation of a few shells. At stage (II), the compositional difference in one single shell can be observed due to the sensitivity of $\mathrm{CaO}$ to pressure. The outer shell of the asymmetric garnet is 
already depleted in $\mathrm{CaO}$. A horizontally truncated zoning profile can be plotted between point $\mathrm{A}$ and $\mathrm{B}$ representing the maximal zoning asymmetry in the last stage (III). Next to the image of stage (II), the magnified part illustrates the numerical structure of the growing garnet. (c) The $P-T$ path and the pressure variation at different temperature points for illustration. The resolution along the $P-T$ path must be set. In the present case, we choose to prescribe the lowest local pressure at the new $P-T$ point to match the highest local pressure at the previous $P-T$ point illustrated with the black horizontal dashed line. Detailed explorations and explanations on this setup is provided in Discussion. The $P-T$ points along the path corresponds to the stages shown in (b).

Fig. 3: (a) Schematic $P-T-P v a r$ grids illustrating the approach defining the starting $P-T-P v a r$ point. Three coordinates represent temperature, pressure and the magnitude of pressure variation. For each starting $P-T-P v a r$ grid, a complete zoning profile can be calculated. The pressure variation constrained by dashed lines indicates the pressure range around the growing garnet. The width of the variation is defined by the amplitude of sinusoidal function in Fig. 1b. (b) An extreme case illustrating both the calculated (blue) and measured (red) profiles with different directions of higher pressure ends. In this case, the measured garnet profile (red) has higher pressure to the right (see red arrow), thus the distance from measured garnet core (peak concentration point) to the right rim is longer than the distance from garnet core to the left rim. Contrarily, the calculated profile (blue) has the opposite high pressure direction pointing leftward. Therefore, the distance from the garnet core to the right rim is shorter than the core to the left rim. This is because the amount of garnet in metamorphic rocks under equilibrium is often higher at higher pressure conditions. The short black arrows indicate the absolute distances between the measurements and the calculated profile. The residual for the calculated zoning profile can be acquired by averaging the distance between the calculated profile and the measured profile (the length of black arrows) through the entire zoning profile. 
Fig. 4: Phase diagram section calculated using Perple_X for three samples. (a) SR123 (Russo et al., 2006), (b) OF2512 (Groppo et al., 2009), (c) TRE 1 (Ballevre et al., 2003). The bulk compositions are given in $w t \%$. The color shades indicate the garnet weight percent. The red curve is the garnet entry curve. In sample OF2512, and sample TRE 1, garnet is stable in the entire $P-T$ space, suggesting that the garnet growth along the prograde $P-T$ path start with a finite amount of garnet. The initial composition and weight percentage of the first shell of the garnet is computed at the starting point on the $P-T$ path without considering the nucleation composition. The star represents the peak $P-T$ conditions listed in Table 1. Mineral abbreviations follow Whitney \& Evans (2010).

Fig. 5: (a) Total residual map sliced at isobaric condition $($ Pvar $=0)$, best fit $P v a r$ at 1 kbar, and the doubled best fit $P$ var at 2 kbar. The stars indicate the peak $P-T$ conditions. The pressure variations are illustrated within the white dash lines around the best fit $P-T$ path. The lowest residual is indicated as black dot in the middle slice. Note the different best fit $P-T$ conditions in the three slices. (b), (c) The total residual as functions of temperature and pressure, respectively. The best fit temperature and pressure changes due to a change of pressure variation. (d) The calculated asymmetric garnet 2D element map and the extracted profiles compared to the measurements plotted with blue dots (Russo et al., 2006). The garnet zoning maps and black profiles are calculated using the best fit $P-T-P v a r$ conditions denoted with the black dot in (a). The dash green profiles are calculated without the pressure variation following the $P$ $T$ path shown in the left residual slice in (a). The profiles are in mole fraction unit.

Fig. 6: (a) Total residual map sliced at isobaric conditions (Pvar=0), best fit $P$ var at $0.75 \mathrm{kbar}$, and the doubled best fit Pvar at $1.5 \mathrm{kbar}$. The stars indicate the peak $P-T$ conditions. The pressure variations are illustrated within the white dash lines around the best fit $P-T$ path. The lowest residual is indicated as black dot in the middle slice. Note the different best fit $P-T$ conditions in the three slices. (b), (c) The total residual as functions of temperature and pressure, respectively. The best fit temperature and 
760

761

762

763

764

765

766

767

768

769

770

771

772

773

774

775

776

777

778

779

780

781

782

783

784

785

786

pressure changes due to a change of pressure variation. (d) The calculated asymmetric garnet 2D element map and the extracted profiles compared to the measurements plotted with blue dots (Groppo et al., 2009). The garnet zoning maps and black profiles are calculated using the best fit $P-T-P v a r$ conditions denoted with the black dot in (a). The dash green profiles are calculated without the pressure variation following the $P-T$ path shown in the left residual slice in (a). The profiles are in mole fraction unit.

Fig. 7: (a) Total residual map sliced at isobaric condition (Pvar=0), best fit Pvar at $0.75 \mathrm{kbar}$, and the doubled best fit $P$ var at $1.5 \mathrm{kbar}$. The stars indicate the peak $P-T$ conditions. The pressure variations are illustrated within the white dash lines around the best fit $P-T$ path. The lowest residual is indicated as black dot in the middle slice. Note the different best fit $P-T$ conditions in the three slices. (b), (c) The total residual as functions of temperature and pressure, respectively. The best fit temperature and pressure changes due to a change of pressure variation. (d) The calculated asymmetric garnet $2 \mathrm{D}$ element map and the extracted profiles compared to the measurements plotted with blue dots (Ballevre et al., 2003). The garnet zoning maps and black profiles are calculated using the best fit $P-T-P v a r$ conditions denoted with the black dot in (a). The dash green profiles are calculated without the pressure variation following the $P-T$ path shown in the left residual slice in (a). The profiles are in mole fraction unit.

Fig. 8: Schematic diagram showing the influence of the equilibrium $P-T$ increment on the asymmetry of garnet growth. The garnet starts to grow from a nucleus in (a) when the $P-T$ conditions first touches the garnet entry isopleth. Fractionation leads to an increase of $P-T$ conditions of the entry isopleth illustrated by the different color solid lines in (b), (c), and (d). Three scenarios can be listed as (b) small $P-T$ increment; (c) large $P-T$ increment, and (d) medium $P-T$ increment. Difference choices of $P-T$ increment result in particular patterns of garnet shape and asymmetry shown in (b), 
787 (c), and (d). The next shell's geometry can be varied depending on the position of next equilibrium $P-T$ conditions.

789 Fig. 9: The influence of the magnitude of pressure variation v. $P-T$ resolution 790 (assigned as temperature increment on the top coordinate). The color indicates total 791 residual of the calculated four end members. The contours are radius ratio of different 792 values, among which the black ones are the measured garnet radius ratio. The white dashed lines indicate the position of $5^{\circ} \mathrm{C}$ temperature increment estimated as a minimal. The position where the contour of the measured radius ratio (black curve) and the estimated temperature increment cross indicates the corresponding magnitude of pressure variation required to grow the observed garnet geometry. Our predicted magnitude of pressure variations ( 0.75 to $1 \mathrm{kbar}$ in Fig. $5 \sim 7)$ are generally below the pressure variation estimated at $5^{\circ} \mathrm{C}$ temperature increment (1.5 to $8.5 \mathrm{kbar}$ ).

Fig. S1: Benchmark comparison of our model with Theria_G (Gaidies et al., 2008). The left images are calculated and presented using Theria_G software package. The crystal size here is the largest one, thus the zoning profiles represent the end member compositions along the entire $P-T$ path. The right plots are calculated using our numerical approach with zero magnitude of pressure variation. Only half the profile is presented for comparison. Slight deviation on the core value (e.g. spessartine and almandine at the core position) might be related to the difference in solid solution or database. The $P-T$ path and bulk composition are provided in Appendix S2. Profiles are illustrated in molar fraction. 


\section{APPENDIX S1}

\section{Procedures of the forward model.}

The numerical model can be streamlined as following:

- Step 1: Start with a model composition that represents the whole rock chemistry; a $P-T$ path experienced by the rock; and a magnitude of pressure variation around the garnet. Parameters such as the number of shell and cell are also set at the beginning. The above is all the parameters required for the numerical model.

- Step 2: Determine the $P-T$ condition in each cell within the first shell as shown in Fig. 1b. The method used in our model is to simply apply a sinusoidal shaped pressure distribution as:

$$
P_{i}=P+P_{v a r} \cdot \sin \left(\frac{2 \pi}{n} i\right)
$$

where $P_{i}$ is the local pressure in cell $i, P$ is the pressure located at the $P-T$ path, $P_{v a r}$ is the magnitude of pressure variation. The number of cell is assigned as $n$.

- Step 3: Use Perple_X to compute the equilibrium garnet modal percentage and garnet chemistry. The input information for Perple_X is the individual pressure within each cell $\left(P_{i}\right)$, a common temperature, and a common effective bulk composition. The results are the equilibrium garnet weight percentage $\left(M_{i}^{\%}\right)$, the volume percentage $\left(V_{i}^{\%}\right)$, and the chemical composition $\left(X_{i}^{\%}\right)$ in each cell $i$.

- Step 4: Assign the system mass to be $M$, and volume to be $V$. The garnet mass and volume of each cell $M_{i}$ and $V_{i}$ are computed by equally distributing the whole system to $n$ cells:

$$
\begin{aligned}
M_{i} & =\frac{M}{n} \cdot M_{i}^{\%}, \\
V_{i} & =\frac{V}{n} \cdot V_{i}^{\%} .
\end{aligned}
$$

- Step 5: Convert $V_{i}$ to radius in 2D model using the equation of sectorial area:

$$
r_{i}^{\text {new }}=\sqrt{\frac{n V_{i}}{\pi}+\left(r_{i}^{\text {old }}\right)^{2}}
$$


in which the thickness of the $2 \mathrm{D}$ model is assumed as unity. $r_{i}^{\text {new }}$ is the radius of the new garnet shell in cell $i, r_{i}^{\text {old }}$ is the radius of the old garnet shell in cell $i$. If $i=1, r_{i}^{\text {old }}$ equals to zero. After the growth of the new layer, the system volume $(V)$ will be updated by subtracting the newly formed garnet volume from the previous system volume.

- Step 6: Fractionate the bulk system composition. The mass conservation requires that:

$$
\underbrace{\left(M-\sum_{i=1}^{n} M_{i}\right) X_{\text {new }}^{\%}}_{\begin{array}{c}
\text { the components mass } \\
\text { without garnet }
\end{array}}=\underbrace{M \cdot X_{\text {old }}^{\%}}_{\begin{array}{c}
\text { the components mass } \\
\text { of the whole system }
\end{array}}-\underbrace{\sum_{i=1}^{n} X_{i}^{\%} \cdot M_{i}}_{\begin{array}{c}
\text { the components mass } \\
\text { of the fractionated garnet }
\end{array}} .
$$

Upon rearrangement, we have:

$$
X_{\text {new }}^{\%}=\frac{M}{M-\sum_{i=1}^{n} M_{i}} \cdot X_{\text {old }}^{\%}-\frac{\sum_{i=1}^{n} X_{i}^{\%} \cdot M_{i}}{M-\sum_{i=1}^{n} M_{i}},
$$

where $X_{\text {new }}^{\%}$ is the new system chemical composition in mass percentage, $X_{\text {old }}^{\%}$ is the old system chemical composition in mass percentage. $X_{\text {new }}^{\%}$ must be normalized for the next round of calculation. After fractionation, the system mass $(M)$ will be updated by subtracting the newly formed garnet mass from the previous system mass. The above equation is slightly different from the classical fractionation model in that the mass of the garnet shell is a sum of mass in all the cells, rather than one uniform value computed in one shell without pressure variation. In case of no pressure variation, the equations can be simplified by neglecting the "sum" signs and changing individual cell's

- Step 7: Record the computed $r_{i}^{\text {new }}$, and chemical composition $X_{i}^{\%}$ in each cell, and return to Step 2 using the new $P-T$ point and the fractionated bulk compositions in Step 6. Repeat the same calculation and record the radius and the composition of garnet at different cell along the $P-T$ path. If the peak $P-T$ point is reached, finish the code.

The final chemical zoning pattern can be plotted using the radius and the composition of the garnet in different cell and shell, which are recorded in Step 7. The initial rock mass $(M)$ and volume $(V)$ will not influence the shape of the 

zoning pattern, but will influence the size of the grown garnet. The corresponding radius can be normalized to the measured garnet radius for comparison purpose.

\section{APPENDIX S2}

\section{Benchmark of the forward model}

To benchmark our forward model, we use the same $P-T$ path and bulk composition as in Gaidies et al. (2008) to calculate garnet zoning profile without pressure variation and compare half of the entire profile with the one calculated using Theria_G. The result of benchmarking is illustrated in Figure $\mathrm{S} 1$ for all the four end members without diffusion.

Differences arise because in our model volume percentage calculated from Perple_X is converted into 2-D trapezoid area in each cell (equivalent to circle when cell number is high enough as illustrated in Figure S1) while in Theria_G the volume percentage is converted to radius in $3-\mathrm{D}$ sphere. This will lead to a difference, especially when the garnet grows larger. However, the results are still comparable in terms of the value range and the shape of the calculated end member molar fraction profile (Fig. S1).

The $P-T$ path and bulk composition are the same as the Loop B in table 3 (Gaidies $e t$ al., 2008) and are provided in the table below. The model system is MnNCFMASH and solid solutions are garnet and staurolite (Holland \& Powell, 1998); plagioclase (Newton et al., 1980); biotite (Tajčmanová et al., 2009); phengite as descripted at (http://www.esc.cam.ac.uk/astaff/holland/ds5/muscovites/mu.html). Chlorite extended from (Holland \& Powell, 1998).

Table S1: the bulk composition of the benchmark model.

\begin{tabular}{|l|l|l|l|l|l|l|l|l|l|}
\hline & $\mathrm{SiO} 2$ & $\mathrm{~A} 12 \mathrm{O} 3$ & $\mathrm{FeO}$ & $\mathrm{MnO}$ & $\mathrm{MgO}$ & $\mathrm{CaO}$ & $\mathrm{Na} 2 \mathrm{O}$ & $\mathrm{K} 2 \mathrm{O}$ & $\mathrm{H} 2 \mathrm{O}$ \\
\hline wt $\%$ & 59.77 & 16.57 & 5.87 & 0.07 & 2.62 & 2.17 & 1.73 & 3.53 & 15 \\
\hline
\end{tabular}

Table S2: the $P-T$ path of the benchmark model. 


\begin{tabular}{|l|l|l|}
\hline Node & $T\left({ }^{\circ} \mathrm{C}\right)$ & $P($ bar $)$ \\
\hline 1 & 446.18 & 3345.11 \\
\hline 2 & 523.58 & 6935.51 \\
\hline 3 & 560.04 & 9270.83 \\
\hline 4 & 567.55 & 9739.58 \\
\hline 5 & 577.10 & 10062.50 \\
\hline 6 & 588.03 & 10145.83 \\
\hline 7 & 601.33 & 9968.75 \\
\hline 8 & 607.14 & 9625.00 \\
\hline 9 & 610.10 & 9229.17 \\
\hline 10 & 606.78 & 8781.25 \\
\hline 11 & 598.26 & 8250.00 \\
\hline 12 & 551.91 & 5687.51 \\
\hline 13 & 454.81 & 3210.71 \\
\hline
\end{tabular}

891 
(a)

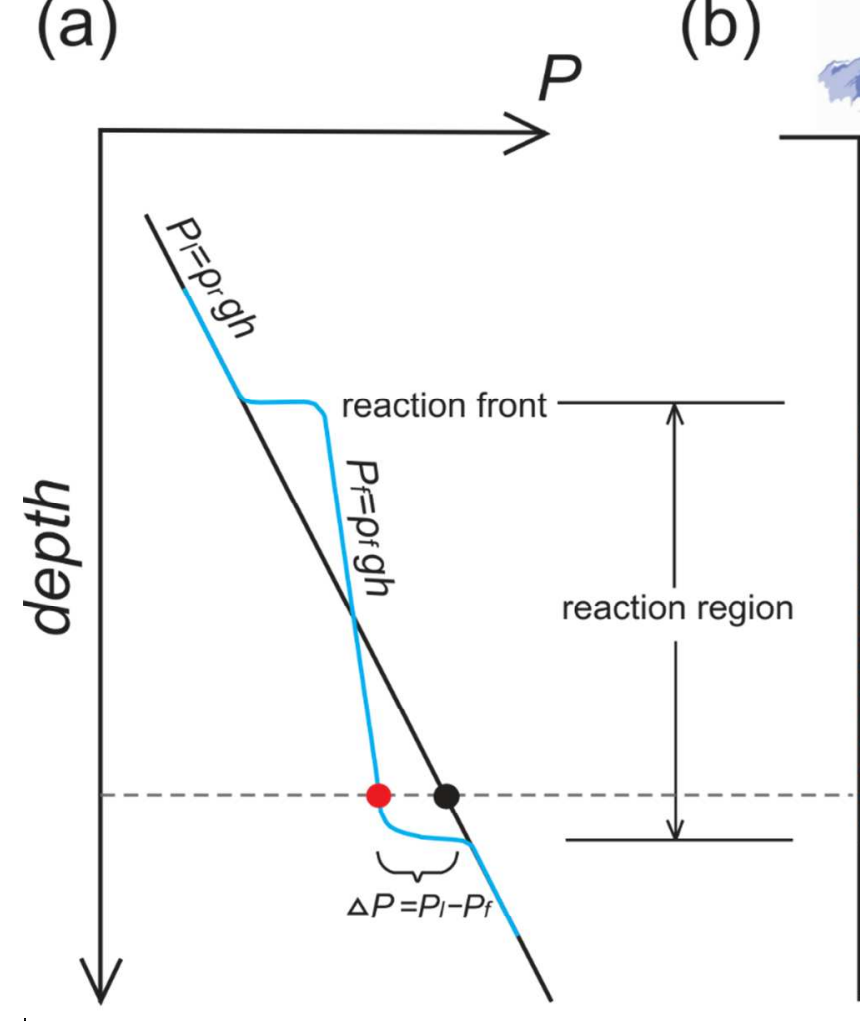

Zhong et al., Fig. 1

(b) an

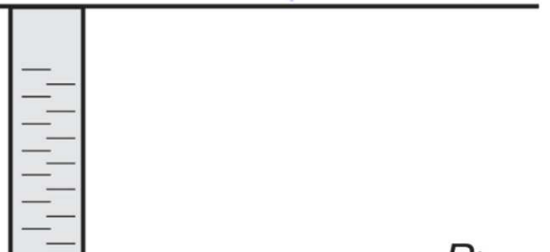

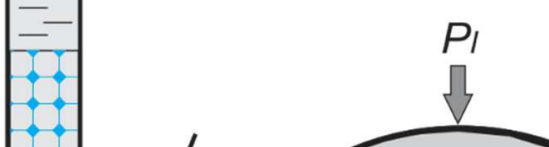
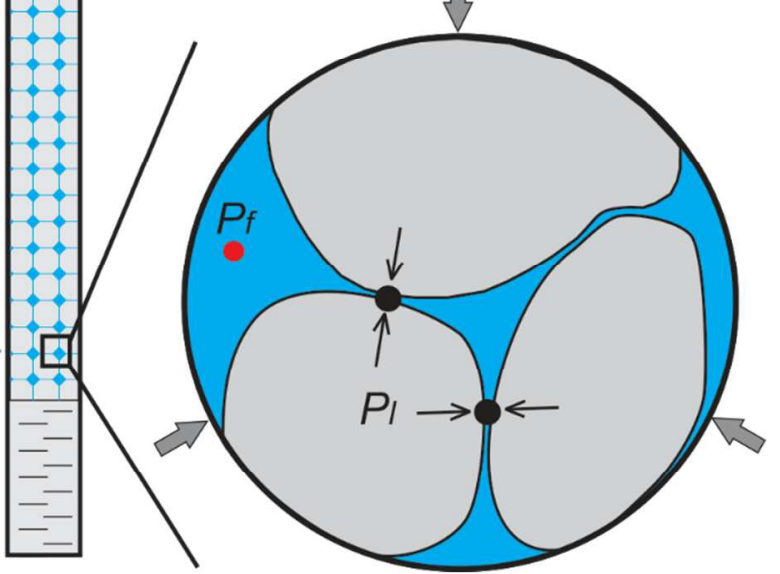
(a) Local pressure variation
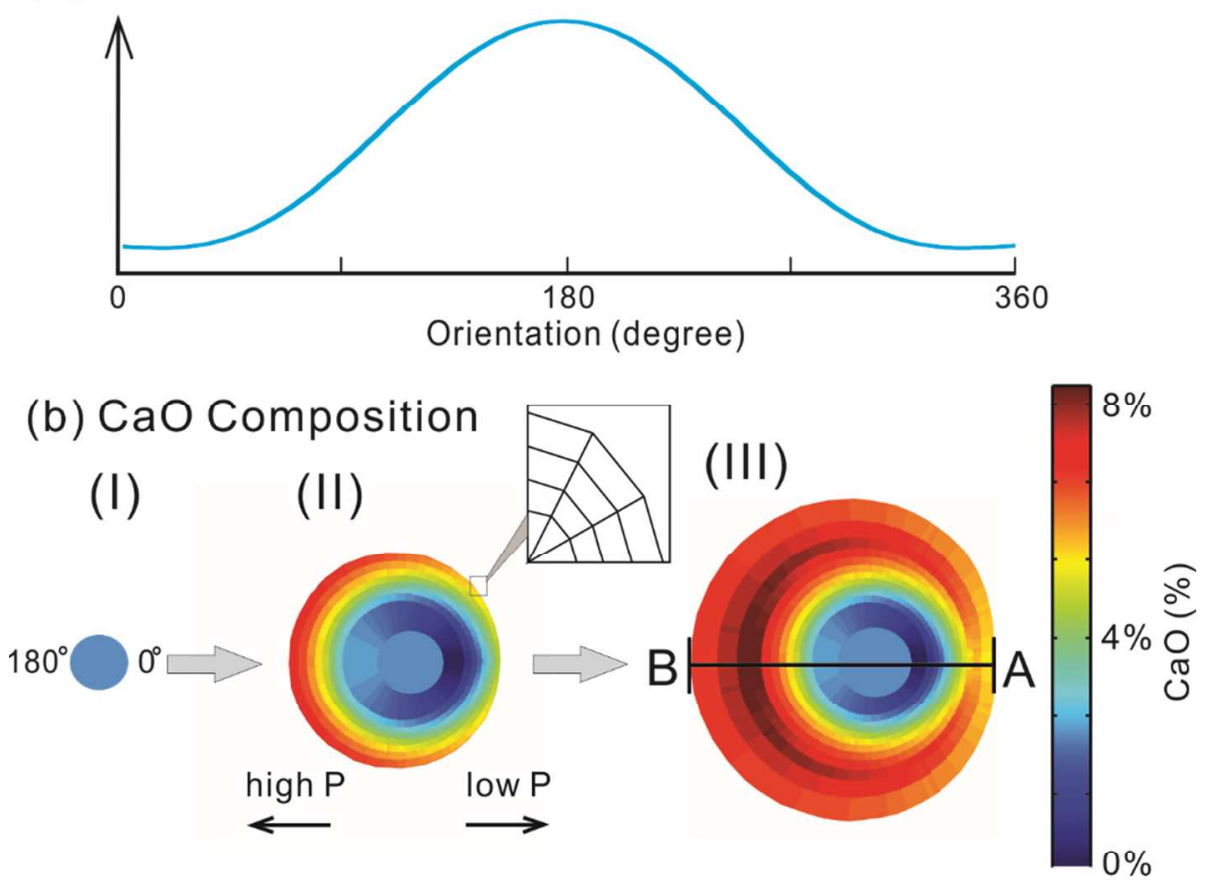

(c) $P-T$ path

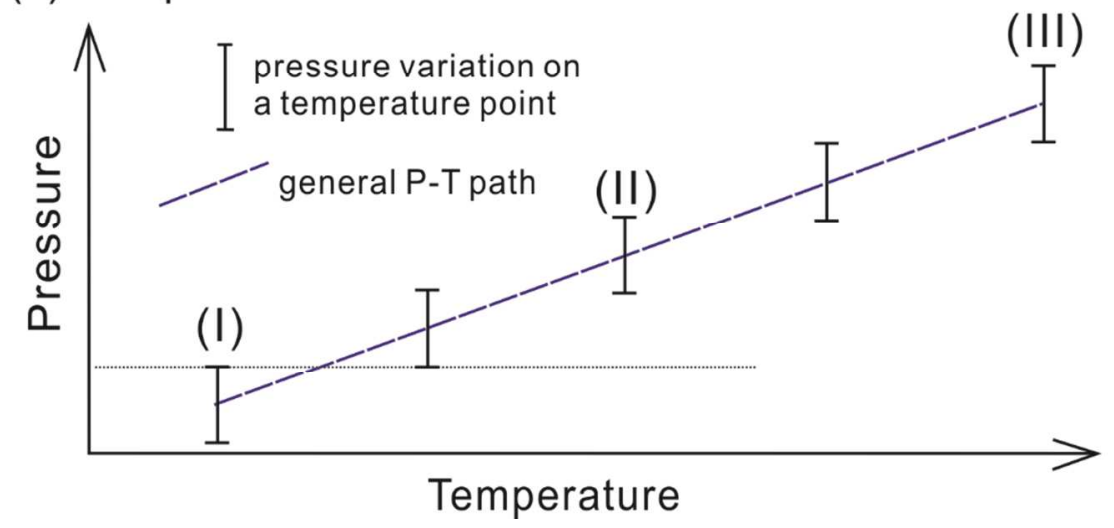

Zhong et al., Fig. 2 

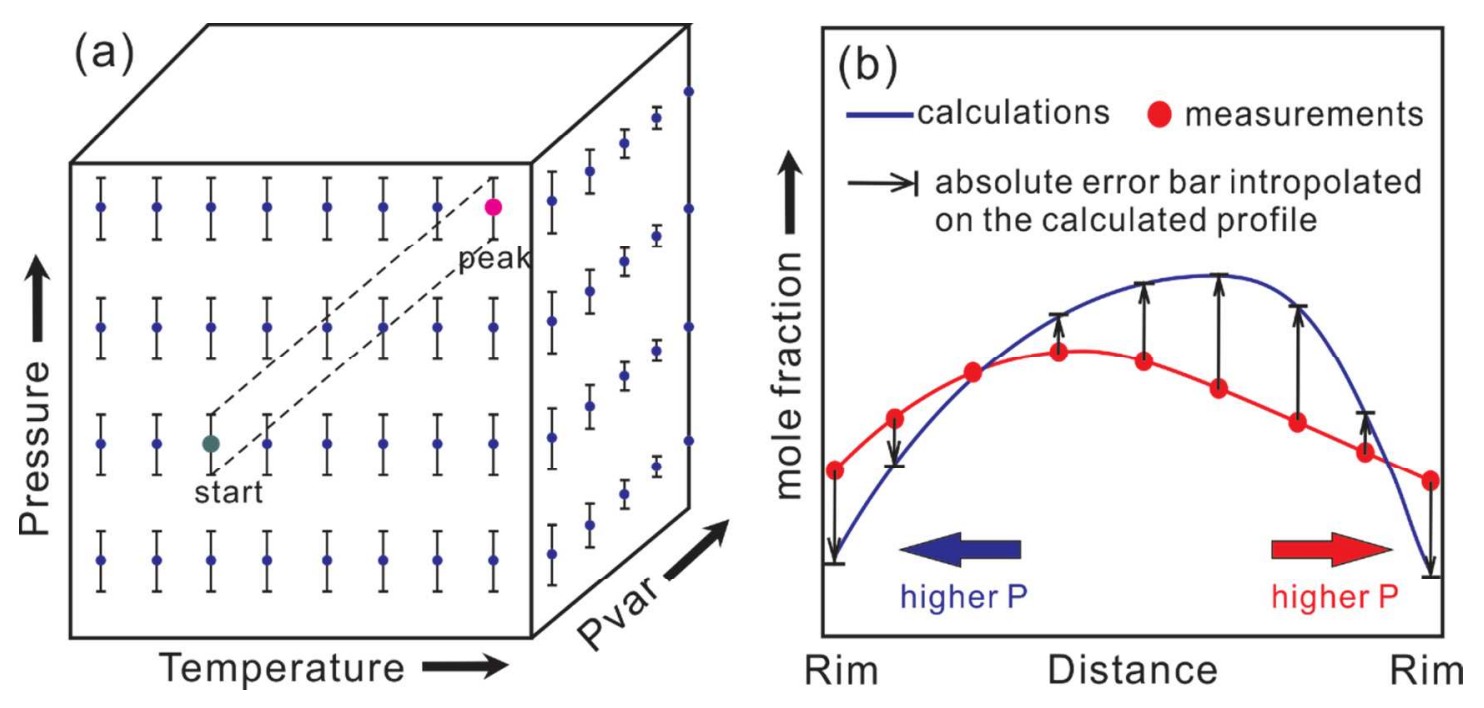

Zhong et al., Fig. 3 
(a) SR123 Qz+H2O in excess

$\mathrm{SiO} 2 \mathrm{Al} 2 \mathrm{O} 3 \quad \mathrm{FeO} \quad \mathrm{MnO} \quad \mathrm{MgO} \quad \mathrm{CaO} \quad \mathrm{Na} 2 \mathrm{O} \quad \mathrm{K} 2 \mathrm{O} \quad \mathrm{H} 2 \mathrm{O}$

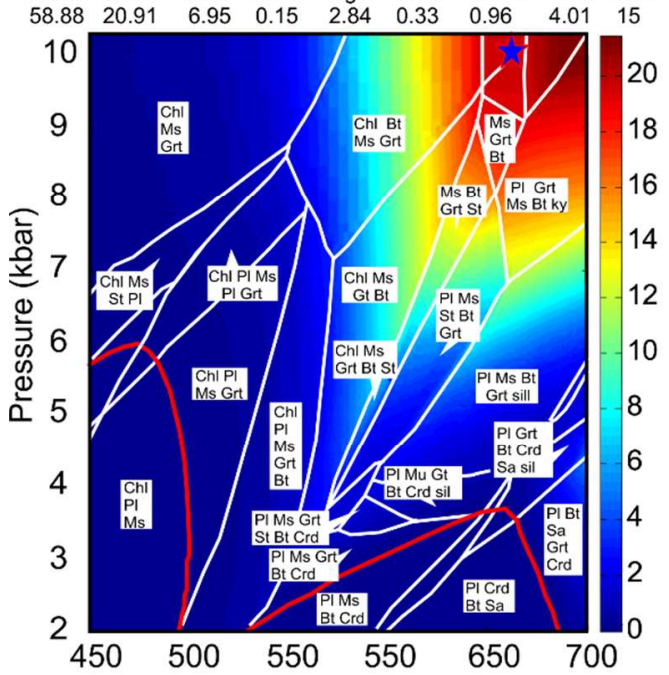

(b) OF $2512 \quad \mathrm{H} 2 \mathrm{O}+\mathrm{Omp}$ in excess

$\mathrm{SiO} 2 \mathrm{Al} 2 \mathrm{O} 3 \mathrm{FeO} \mathrm{MnO} \mathrm{MgO} \quad \mathrm{CaO} \mathrm{Na} 2 \mathrm{O} \mathrm{K} 2 \mathrm{O} \quad \mathrm{H} 2 \mathrm{O}$ $\begin{array}{lllllllll}50.20 & 15.35 & 9.77 & 0.16 & 5.82 & 8.88 & 4.62 & 0.26 & 15\end{array}$

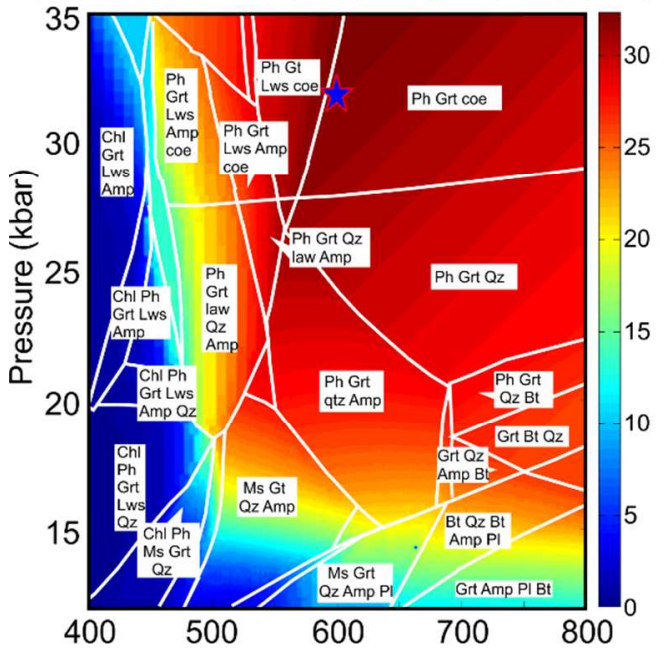
(c) TRE 1
$\mathrm{Qz}+\mathrm{H} 2 \mathrm{O}$ in excess $\begin{array}{lllllllll}\mathrm{SiO} 2 & \mathrm{Al} 2 \mathrm{O} 3 & \mathrm{FeO} & \mathrm{MnO} & \mathrm{MgO} & \mathrm{CaO} & \mathrm{Na} 2 \mathrm{O} & \mathrm{O} 2 & \mathrm{H} 2 \mathrm{O} \\ 44.76 & 16.29 & 9.44 & 0.30 & 4.14 & 7.34 & 2.64 & 0.07 & 15\end{array}$

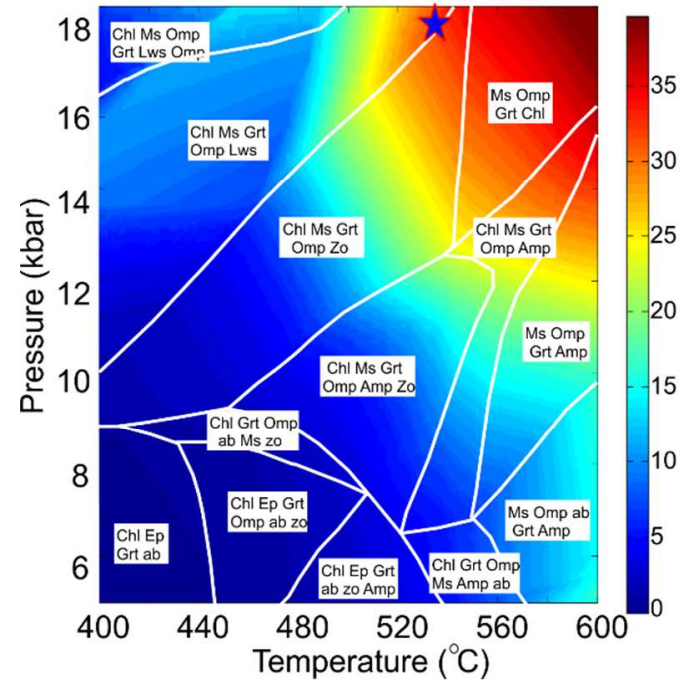

Zhong et al., Fig. 4 


\section{Page 41 of 72}

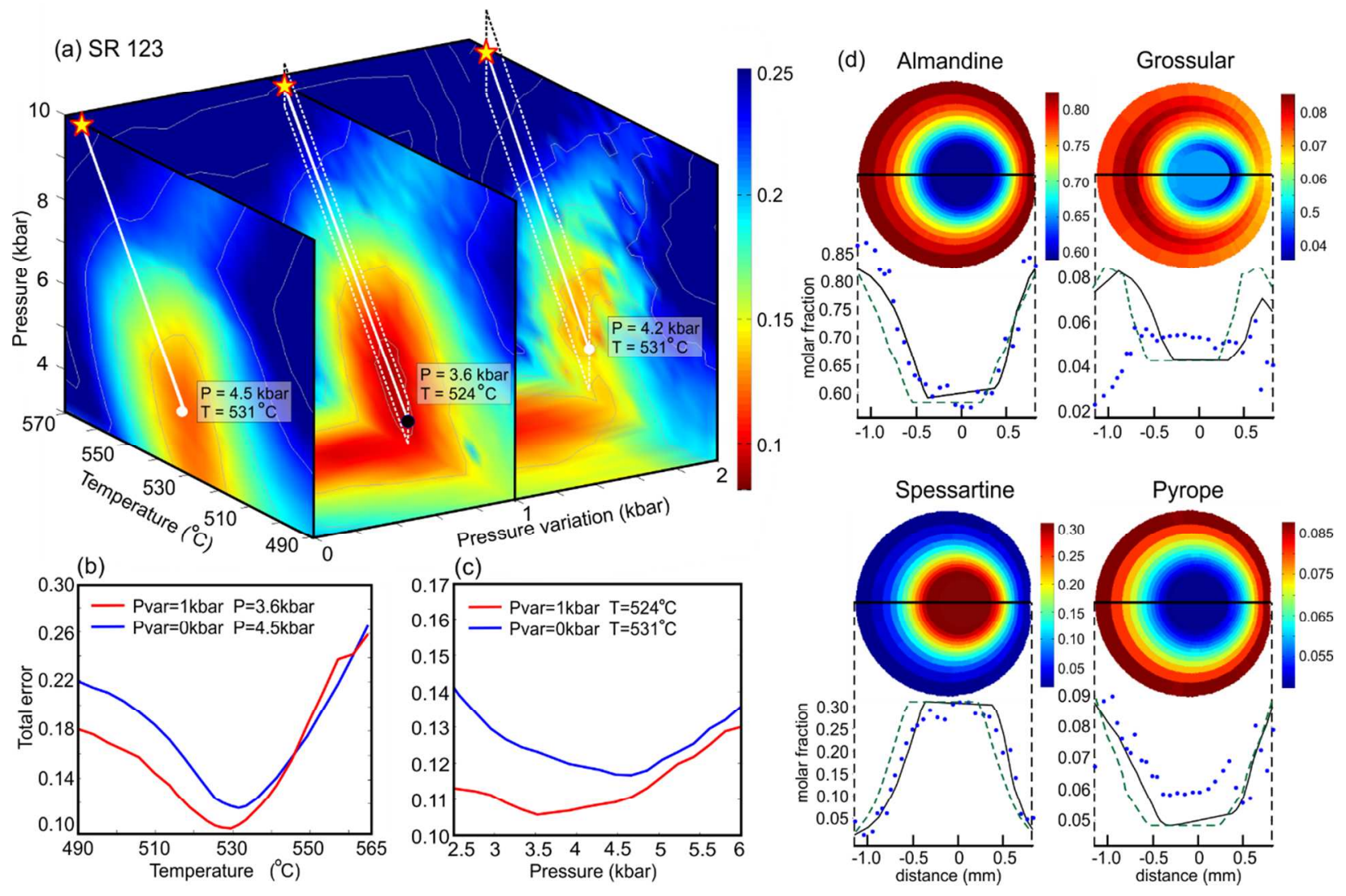

Zhong et al., Fig. 5 


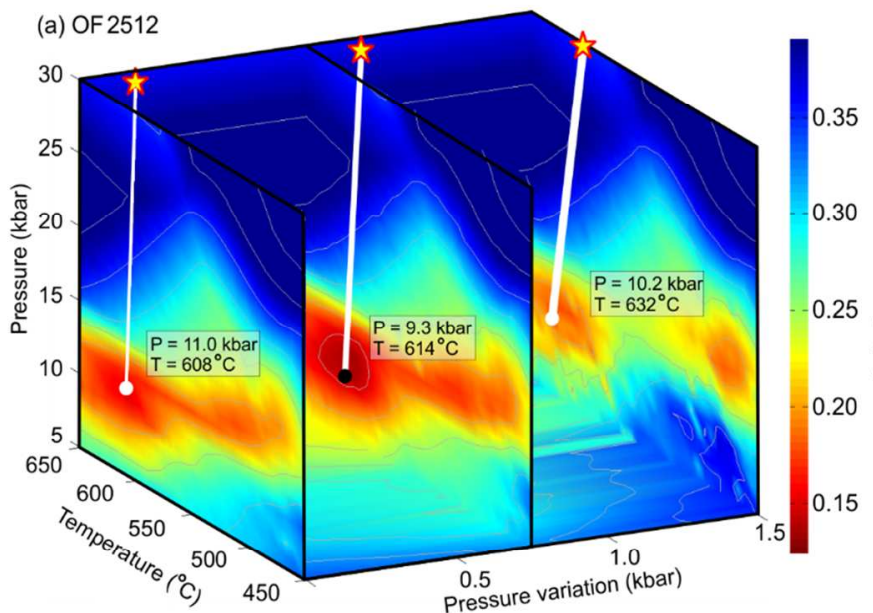

(d) Almandine
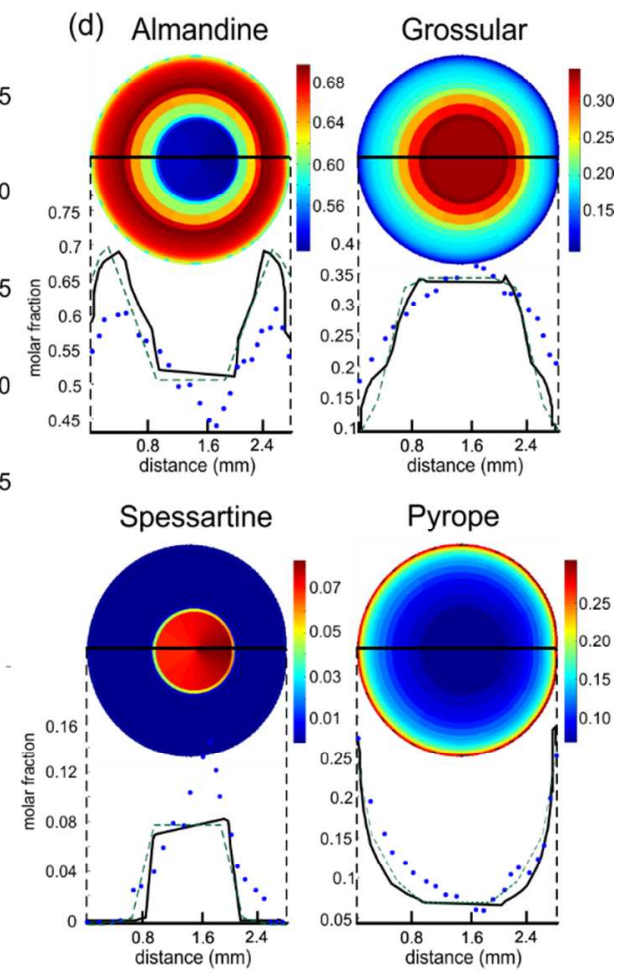

Zhong et al., Fig. 6 


\section{Page 43 of 72}
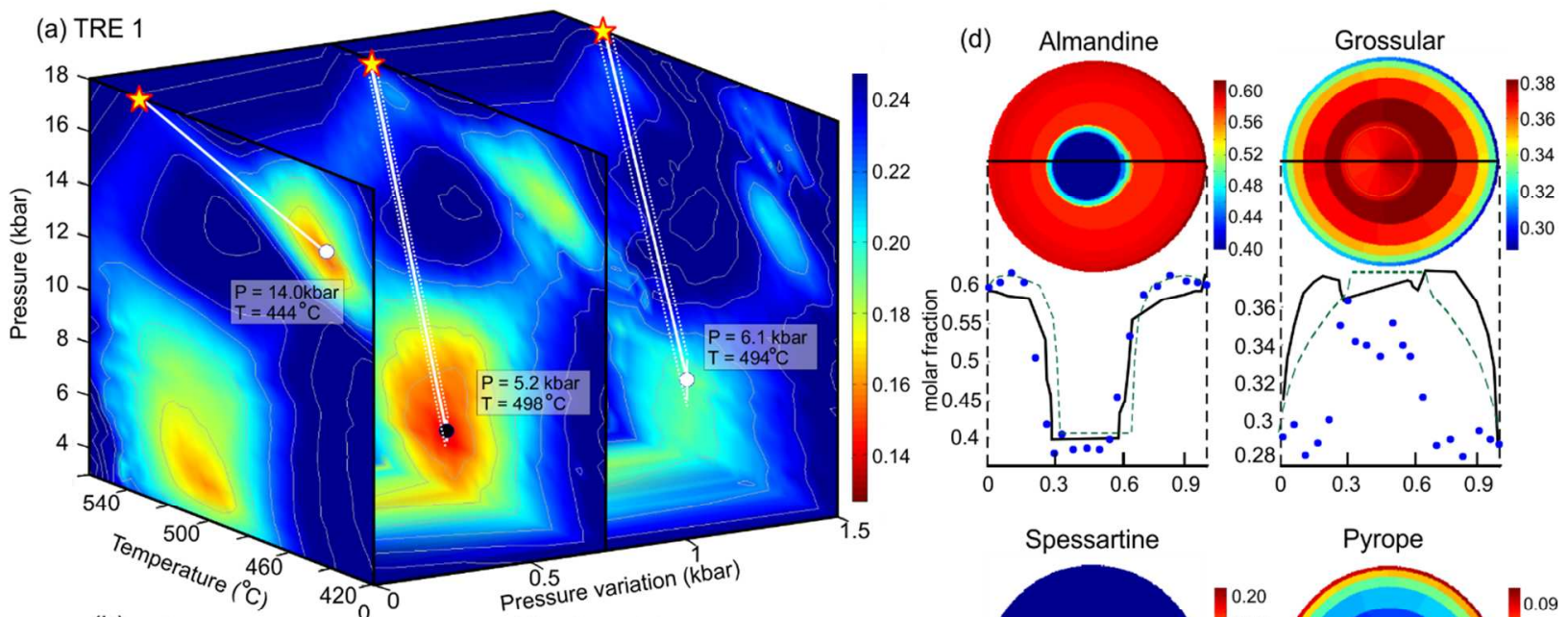

(b)

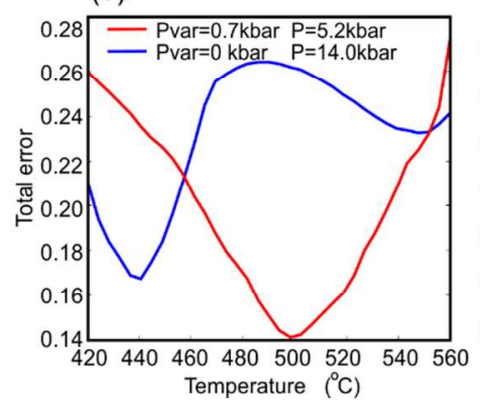

(c)
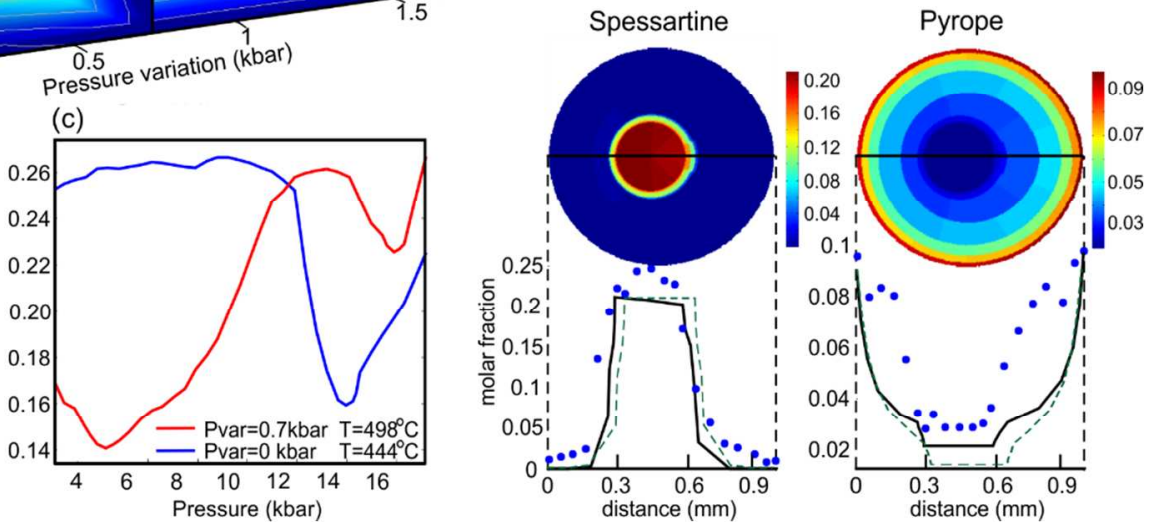

Zhong et al., Fig. 7 
(a) first entry

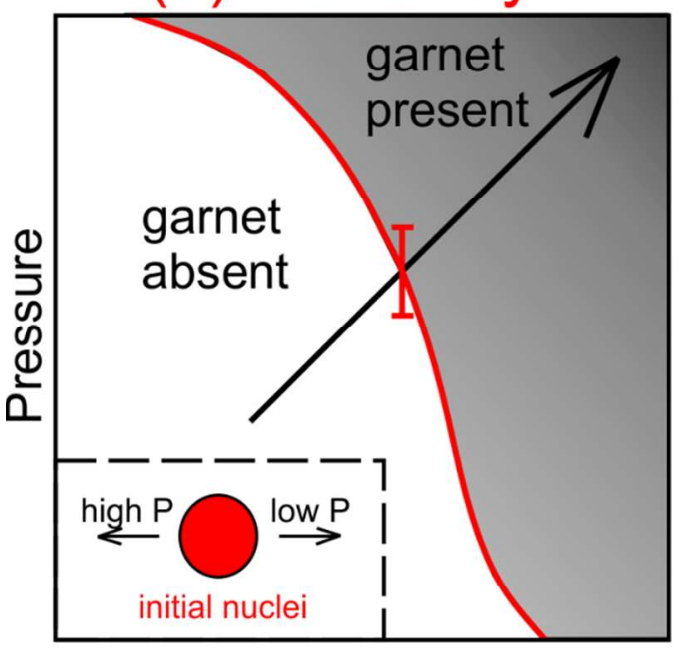

(c) large increment

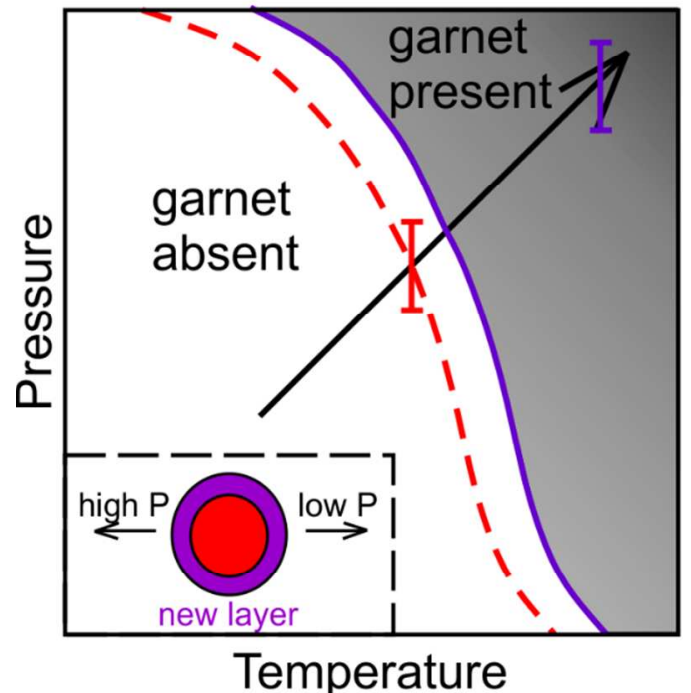

(b) small increment

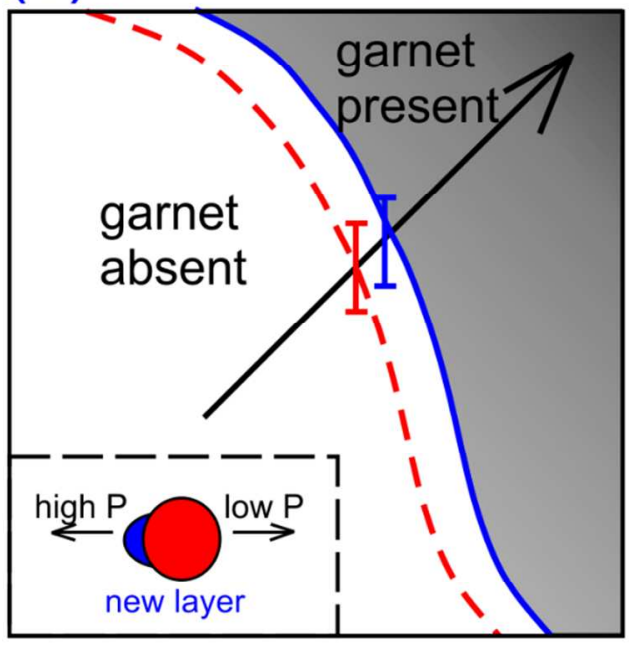

(d) medium increment

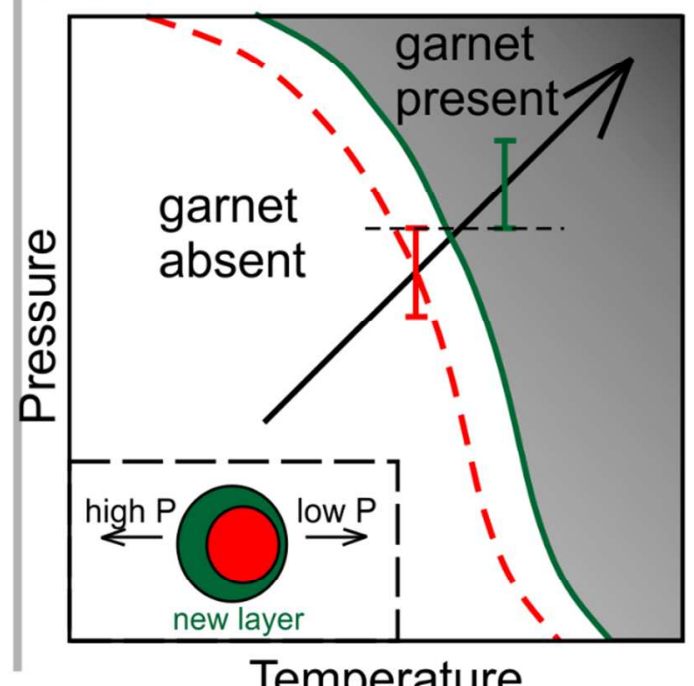

Temperature

Zhong et al., Fig. 8 


\section{Page 45 of 72}

(a) SR 123 Equilibrium Temperature Increment ${ }^{\circ} \mathrm{C}$
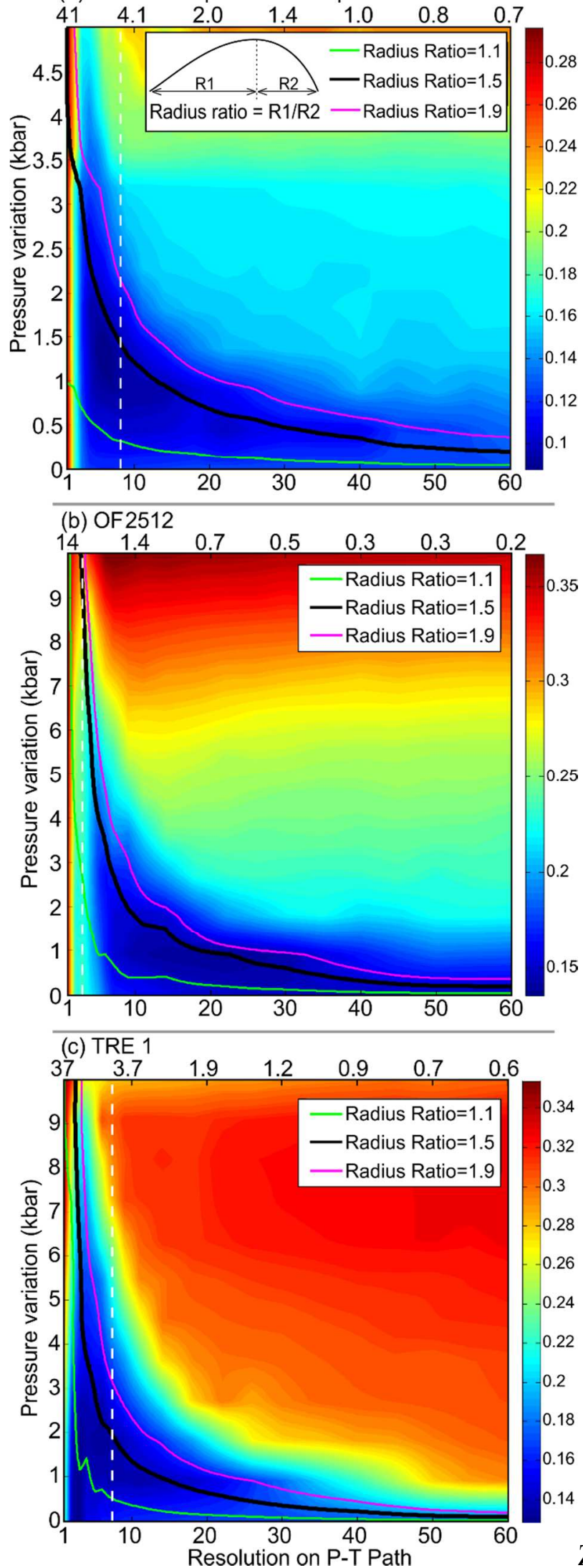

Zhong et al., Fig. 9 

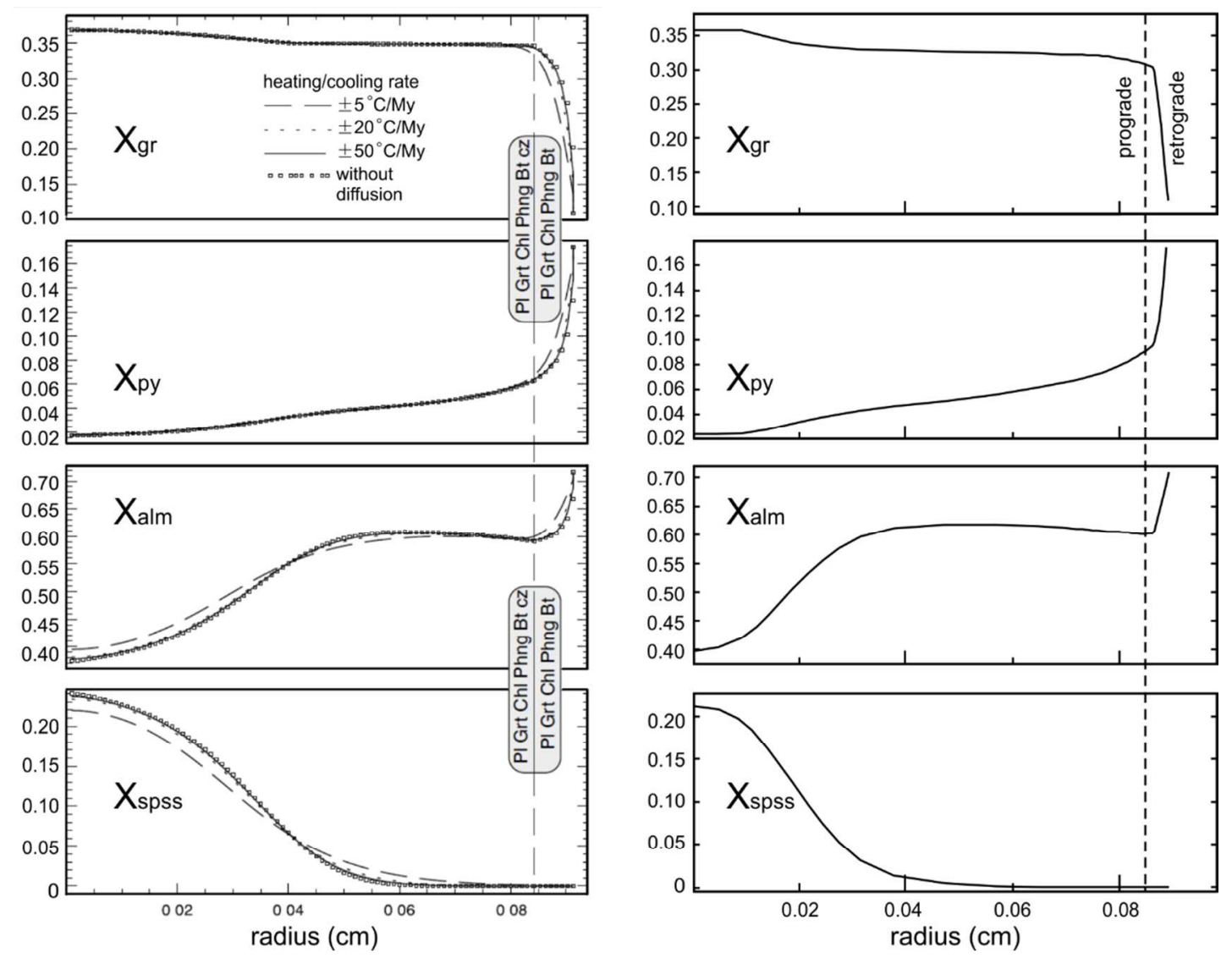

Zhong et al., Fig. S1 